Dario Álvarez

Figura 1. R. Burle Marx. "Las bañistas", dibujo Jardin Wallerstein, Teresópolis 1938 (Montero, 2001).

Dario Álvarez Álvarez.

Departamento de Teoría de la Arquitectura y Proyectos Arquitectónicos Escuela Técnica Superior de Arquitectura de Valladolid.

\title{
El surrealismo en los paisajes de Burle Marx
}

\author{
"Roberto Burle Marx pinta con plantas" Lucio Costa
}

Palabras clave: Roberto Burle Marx, paisaje moderno, jardin del ministerio, Surrealismo, Biomorfismo, Jean Arp.

El artista brasileño Roberto Burle Marx revolucionó por completo el diseño del paisaje moderno en la década de 1930, al proyectar el jardin de la terraza del Ministerio de Educación y Salud de Río de Janeiro en clave pictórica, inventado un asombroso mecanismo compositivo en el que el surrealismo biomórfico bidimensional se convertía en un espacio paradisiaco en tres dimensiones construido integramente con plantas. Tomando como referencia las obras de Jean Arp, Burle Marx generó un procedimiento de superposición de capas al mismo tiempo cromáticas y vegetales, sumando su hallazgo a los que se habian producido en Europa en la década anterior de la mano del resto de las vanguardias plásticas, con la aportación de los arquitectos modernos. El resultado es un ejercicio de antropofagia cultural mediante el cual las curvas sensuales del paisaje brasileño se tornan abstracciones surrealistas, contaminando con ello la producción de arquitectos como Oscar Niemeyer.

En un dibujo de 1938 titulado "Las Ebañistas", el artista brasileño Roberto Burle Marx (1909-1994) representa a un grupo de mujeres que se bañan desnudas en un curso de agua situado en el claro de un bosque, recreando lo que parece un paraíso natural, con presencia de abundante vegetación tropical que enmarca y empequeñece notablemente las delicadas figuras. La minuciosa y detallada representación de los elementos vegetales contrasta deliberadamente con la libertad formal de los despreocupados cuerpos femeninos. La escena parece evocar dos pinturas de Henri Matisse de 1906, "Joie de vivre" y "Pastoral", inspiradas a su vez en otras obras del gran pintor paisajista francés del XVII Nicolas Poussin. Sin embargo, tras su apariencia, el dibujo no es solo un ejercicio artístico, sino que ilustra el diseño del jardín de Louis Wallerstein en Teresópolis, y escenifica un espacio de una sensualidad desbordante, un jardín concebido como un paraíso en medio de una exuberante selva tropical. Esta imagen de un paraíso no natural pro-

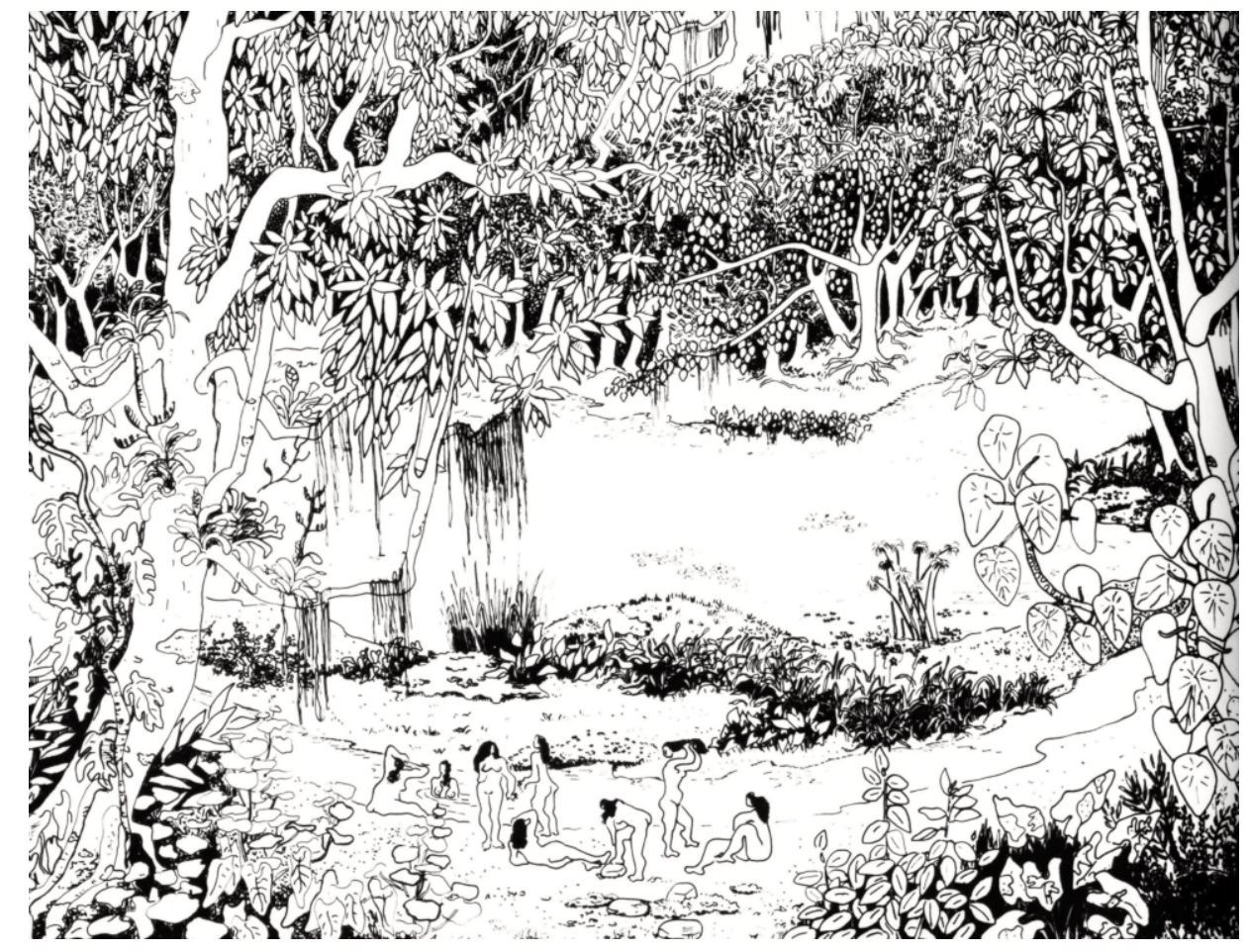


ducto de la intervención humana es una de las constantes en la obra del artista brasileño, uno de los grandes creadores del paisaje moderno.

Los dibujos con los que Burle Marx ilustra espacialmente sus diseños de jardines sorprenden por su elaboración figurativa si los comparamos con sus representaciones en planta, composiciones plásticas con un alto grado de abstracción, manchas biomórficas claramente deudoras del surrealismo. Esto se hace evidente en los jardines de su primera época, como el de la casa Hungría Machado, el de la cubierta del Instituto de Seguros de Brasil, el de la Plaza Salgado Filho en el Aeropuerto Santos Dumont y, sobre todo, el del Ministerio de Educación y Salud, todos ellos en Río de Janeiro, obras singulares que constituyen, a finales de la década de 1930, una gran aportación (en realidad una verdadera revolución) de Burle Marx al desarrollo del jardin de las vanguardias. En todas estas obras encontramos un doble enfoque del artista: cuando representa la planta del jardín, normalmente mediante gouache, su pincel es abstracto y surrealista, mientras que cuando representa el espacio, mediante tinta, su pluma se decanta por un amable realismo lírico. Frente al rigor geométrico de la vanguardia europea, el artista brasileño opta por un mundo personal en el que las formas surrealistas se tiñen de tropicalismo en un ejercicio magistral en el que están presentes el ritmo y el pulso de toda una cultura y un modo de sentir la vida y de disfrutarla.

\section{Jardin y pintura}

La intensa relación entre jardín y pintura que se produce en la obra de Burle Marx continúa una larga tradición ya iniciada en el antiguo jardín romano (a través de las representaciones pictóricas de paisajes y jardines en los muros de los patios-jardin de las casas) y en el oriental (los paisajes de rocas pintados por los chinos que inspirarian sus propios jardines primero y posteriormente los de Japón). Tradición que se continúa con los grandes hallazgos perspectivos, entre pictóricos y arquitectónicos, del manierismo italiano y del barroco francés, especialmente en las obras de André Le Nôtre (auténticas ilusiones ópticas tridimensionales) inspiradas por la pintura de Nicolas Poussin, hasta el sentido picturesque del jardín inglés del siglo XVIII, configurando escenas bucólicas y pastoriles, como las de los cuadros que adornaban las casas de sus propietarios, copias de obras de Claude Lorrain o el mismo Poussin. Si bien los jardines decimonónicos parecieron evitar toda referencia pictórica en busca de un mayor naturalismo, la aparición de los primeros indicios de las vanguardias, en los albores del siglo XX, permitió recuperar la relación entre jardín y pintura, abriendo un interesante campo de investigación formal. En la década de 1920, los arquitectos redescubrieron la pintura como fuente de inspiración del jardin; todos los "ismos" lo fueron: cubismo, purismo, expresionismo o neoplasticismo (Álvarez 2007). Baste citar algunos ejemplos, como el jardín expresionista de la casa Kallenbach (Berlín, 1922) de Walter Gropius y Adolf Meyer, o los dos jardines cubistas realizados en la Exposición de las Artes Decorativas de París de 1925 por Robert Mallet-Stevens (con sus tan celebrados como criticados árboles de hormigón, obra de los escultores hermanos Jan y Joël Martel) y Gabriel Guévrékian ("Jardin d'eau et de lumière", reinterpretando en clave de micropaisaje triangular el simultaneísmo del matrimo-
Figura 2. R. Burle Marx. Plaza Salgado Filho, aeropuerto Santos Dumont, Río de Janeiro, 1938. Planta (Rizzo, 1992).

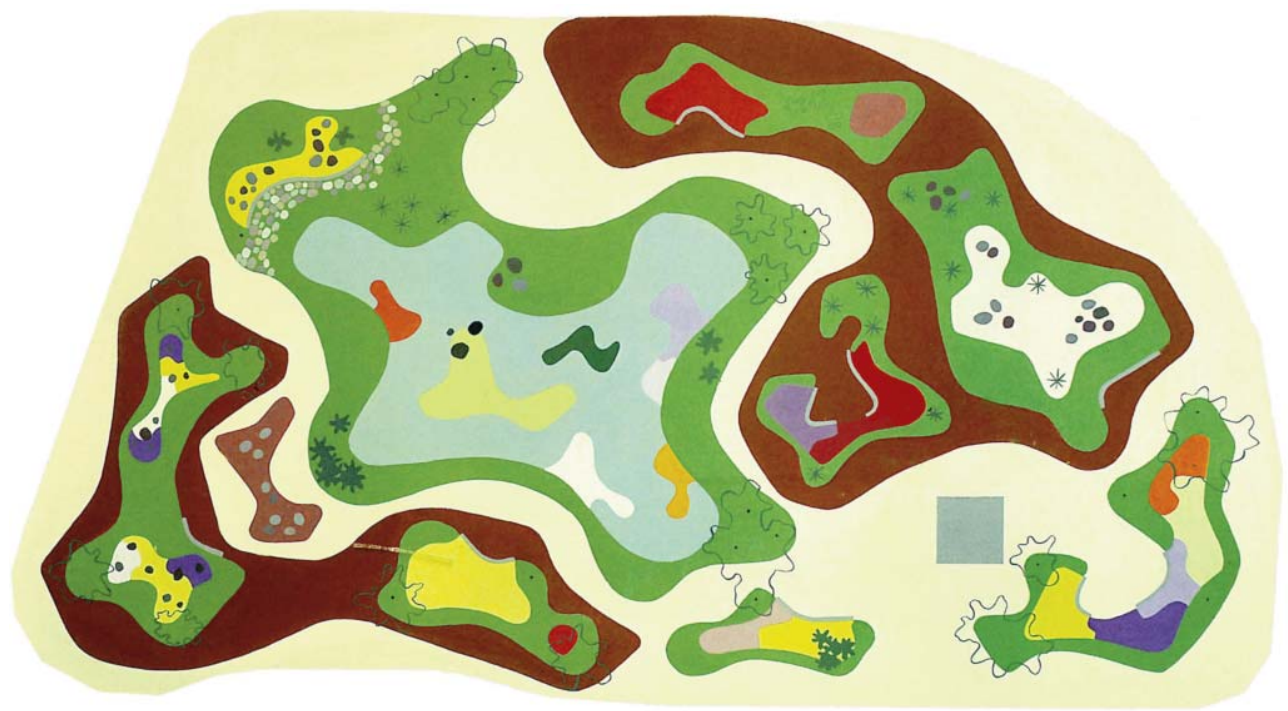




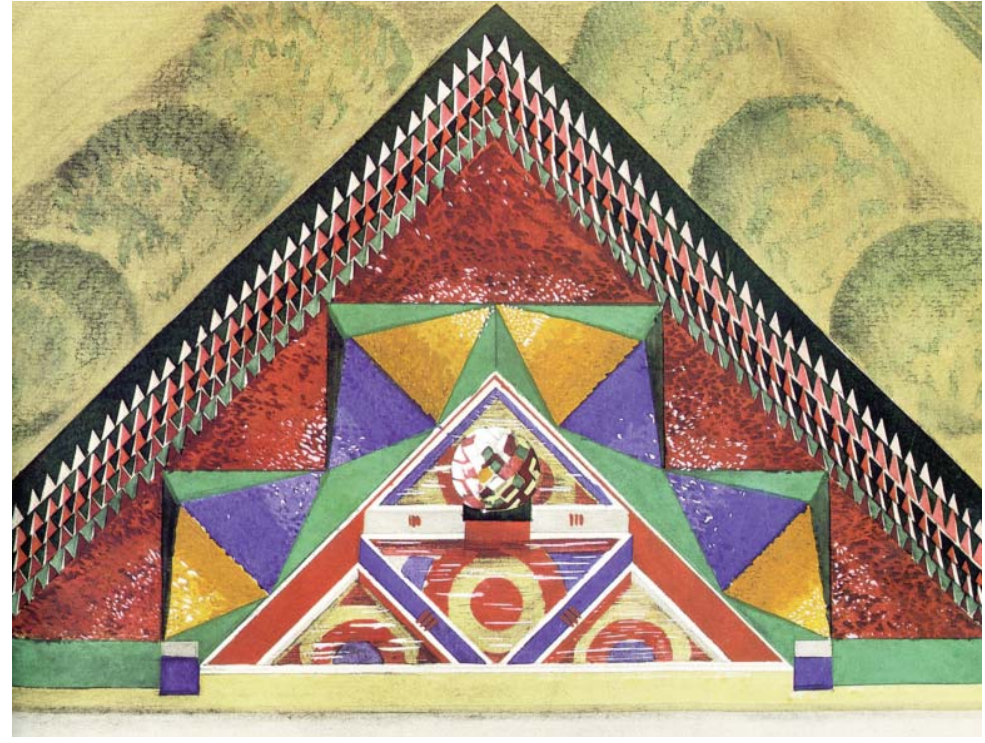

Figura 3. G. Guévrékian. Jardín de agua y de la luz, Exposición de las Artes Decorativas de Paris, 1925 (Imbert, 1993). nio formado por Sonia y Robert Delaunay, que pintó los fondos del estanque), o el jardín neoplástico de la Casa Rosenberg (1922), proyectada por los arquitectos G. Rietveld y C. Van Esteren junto al pintor Theo Van Doesburg. Estos y otros experimentos similares abririan el camino para que unos años más tarde Burle Marx concibiera y diera forma a un jardín concebido y formalizado en clave netamente surrealista.

Roberto Burle Marx se había aficionado al jardin antes que a la pintura; su madre, Cecilia Burle (una dama culta de Pernambuco, con antepasados portugueses y franceses), además de pianista y cantante (otro de sus hijos, Walter, sería un famoso pianista y compositor) era una gran enamorada de las plantas y enseñó al joven Roberto los conocimientos básicos para el cuidado del jardín familiar en la casa de Río de Janeiro. A principios de los años 1920, su padre, Wilhelm Benjamin Marx, judio de origen alemán (nacido en Trier y emparentado con Karl Marx), le trajo de un viaje a Suiza varios ejemplares de la revista alemana Gartenschönheit ( $E l$ jardin de la belleza), cuya lectura, según confesaría el propio Burle Marx, influyó en él de manera notable. La revista era una prestigiosa publicación dirigida por los paisajistas Karl Foerster y Camillo Schneider (ambos, con Hermann Mattern, diseñaron en 1928 el jardín de la Villa Müller en Praga de Adolf Loos) que se editó desde 1920 hasta 1941; en ella colaboraron autores de la talla del arquitecto paisajista Leberecht Migge, que había revolucionado el arte del paisaje en Alemania a través de sus manifiestos verdes y de sus colaboraciones con arquitectos como Bruno Taut o Martin Wagner. Podemos imaginar que a través de la revista el joven brasileño pudo conocer de primera mano algunas de las obras de jardín más destacadas de la primera modernidad y tomar contacto con ella.

En 1928 la familia se trasladó temporalmente a Berlín, en parte para tratar unos problemas de visión de Roberto y en parte para cumplir el empeño de su padre de completar la formación cultural de sus hijos en su Alemania natal. Durante los dos años que duró su estancia berlinesa de la familia, el joven Roberto, además de escuchar a Wagner y conocer la música de vanguardia -Paul Hindemith, Arnold Schönberg, Alban Berg-, descubrió la pintura moderna. En una gran retrospectiva de la obra de Van Gogh se quedó fascinado por la luz de sus cuadros, lo que hizo que empezara a asistir a clases de pintura en el taller de Degner Klemn, y que conociera la obra de Paul Klee, Henri Matisse y Pablo Picasso en sus visitas a la Galeria Flechtheim; en palabras del artista: "Se ha dicho que estuve influenciado por Picasso, sí fui influido por él y no tengo miedo de las influencias. Si comenzamos a analizar una obra de Picasso podemos encontrar influencia de toda la pintura, claro que él fue un genio que supo absorber y crear algo propio" (Oliveira 2007). Por otro lado, en el jardín botánico de Dahlem hizo otro gran descubrimiento, la vegetación autóctona brasileña que no conocía, ya que apenas se utilizaba en los jardines en Brasil, sometidos desde el siglo XIX al gusto europeo; este encuentro con la vegetación de su país le produjo un impacto similar al que le había producido la pintura; su refinada inteligencia comenzó a asociar ambas cosas para forjar un camino personal futuro: "En Dahlem, en un día memorable, encontró grupos de elegantes palmeras, filodendros con hojas enormes, marantas con hojas que parecian pintadas en diferentes estampas, caladios que ya conocía y orquídeas fantásticas, todo de Brasil. Un poco más adelante había un grupo de cactus, también de Brasil. Y él también era de Brasil. Fue un choque, un reconocimiento placentero de que, en cierto sentido, eran sus plantas (...), entonces comenzó a darse cuenta de que era esencial elaborar un vocabulario personalizado si quería dedicarse a la jardinería en serio" (Fleming 1996).

En 1930, a su vuelta a Brasil, Burle Marx se inscribió en la Escuela Nacional de Bellas Artes de Río de Janeiro con la intención de cursar estudios de arquitectura, pero Lucio Costa, amigo de la infancia y en ese momento director de la Escuela, le 
Figura 4. L. Costa y G. Warchavchki, con R. Burle Marx. Jardin de la casa Schwartz, Rio de Janeiro, 1932 (Adams, 1991).
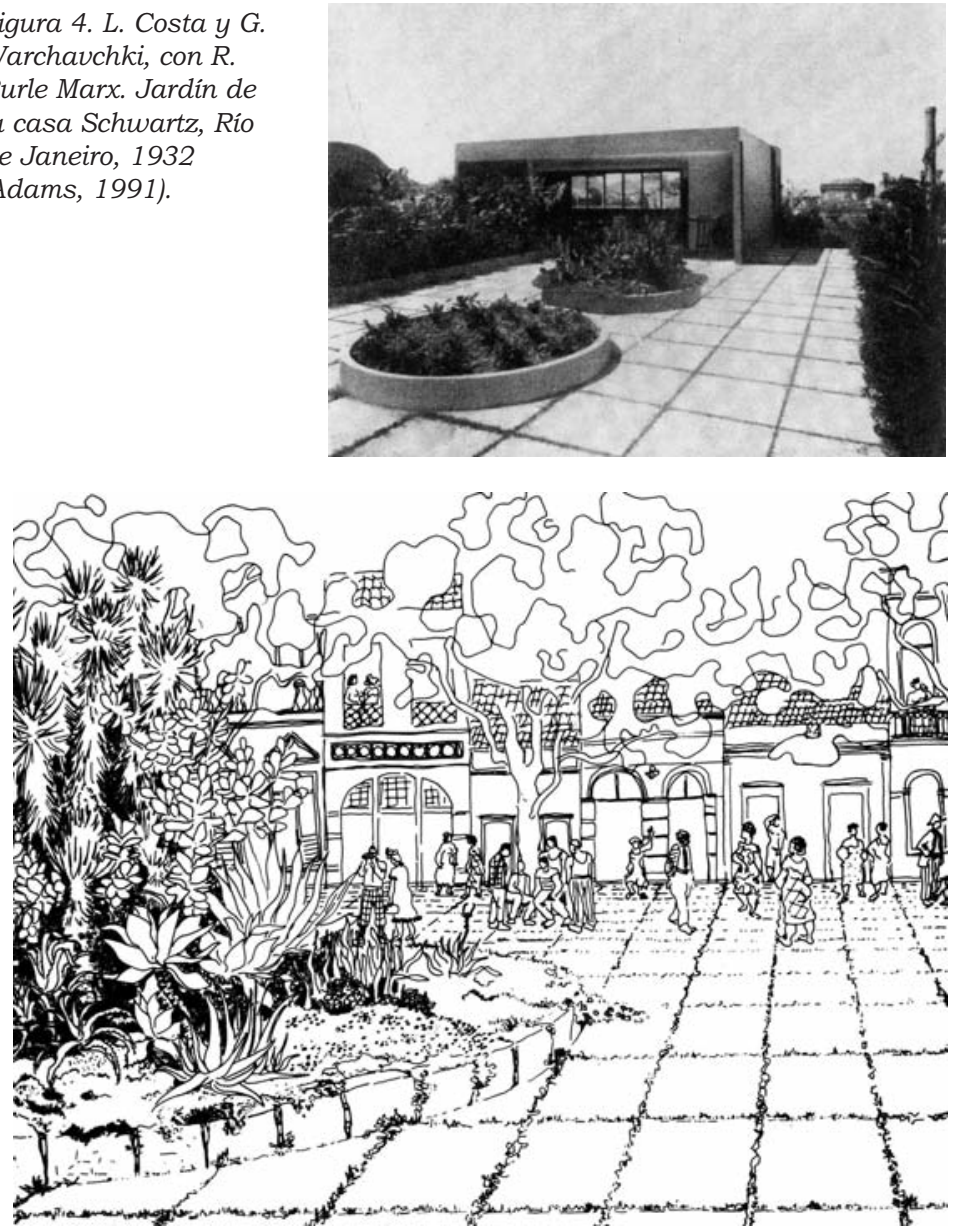

Figura 5, derecha. $R$. Burle Marx. Plaza Arthur Osias, Recife 1935 (Tabacow, 2004).

Figura 6. Le Corbusier. Propuesta para el Ministerio de Educación, Río de Janeiro, 1936. Vista general (Le Corbusier, 1975). convenció para que estudiase pintura, disciplina para la que, según él, presentaba una mayor aptitud, tras su primer aprendizaje europeo (Montero 2001). En la Escuela de Bellas Arte conoció a los estudiantes de arquitectura Oscar Niemeyer y a los hermanos Marcelo y Milton Roberto, con quienes colaboraria de manera muy fructífera años después, especialmente con el primero. Burle Marx recordaría de entre todos sus profesores en la Escuela al pintor Leo Putz, pintor alemán afincado en

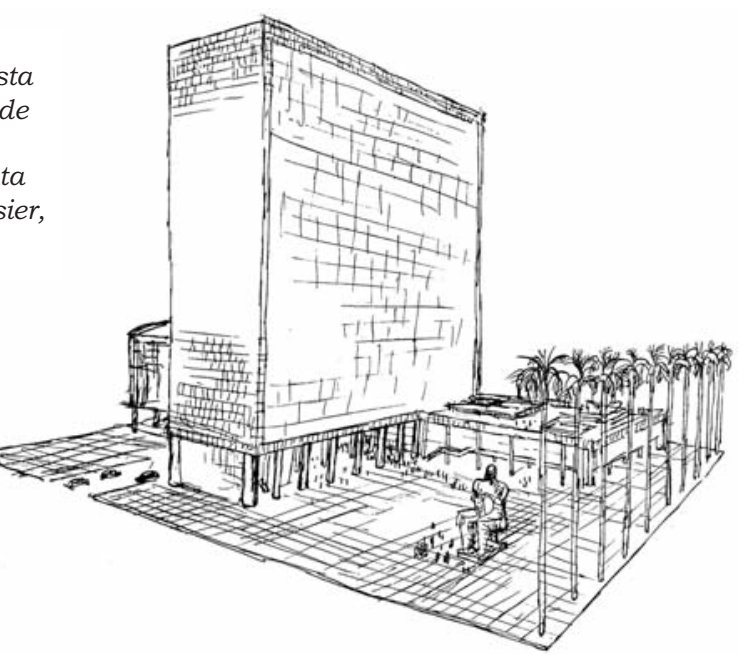

1929 en Brasil $^{1}$, quien le inició en la pintura de paisajes y en la lectura e interpretación de las formas de la naturaleza; Putz se había especializado en la representación de desnudos femeninos en paisajes, temática que repetiria a menudo el propio Burle Marx, como en el mencionado dibujo de "Las bañistas".

En 1932 Burle Marx tuvo la oportunidad de colaborar con Lucio Costa y Gregori Warchavchki (arquitecto nacido en Rusia y afincado en Brasil en 1923) en el diseño del jardín en la terraza de la casa de Alfredo Schwartz en Copacabana, una de las primeras obras modernas brasileñas; tanto la casa como el jardin presentaban claras resonancias corbusierianas. ${ }^{2}$

En 1934 el Gobernador de Pernambuco, Lima Cavalcanti, tras conocer casualmente el jardín de la casa Schwartz, ofreció a Burle Marx el puesto de director de los jardines de la ciudad de Recife, en donde estuvo dos años interviniendo en jardines y plazas públicas, muy interesantes desde el punto de vista botánico, pues comenzó a utilizar todo tipo de vegetación autóctona, pero no demasiado desde el punto de vista compositivo, ciñéndose a una estética sobria, aunque los dibujos preparatorios de los proyectos denotan un claro tinte expresionista que la realidad construida atenúa por completo. Solo en algún proyecto, como el de la plaza de Arthur Oscar (1935), el dibujo se vuelve más libre, más intuitivo y personal, y parece anticipar hallazgos formales posteriores próximos al surrealismo.

\section{El jardin del Ministerio}

En 1936, debido a cuestiones políticas, Burle Marx abandonó el cargo de Recife y se instaló en Río de Janeiro, resuelto a trabajar como pintor y paisajista, en donde realizaria, colaborando con su amigo Lucio Costa, un auténtico manifiesto del paisaje moderno, el jardín para el Ministerio de Educación y Salud (actualmente Palacio Capanema), símbolo de la aceptación oficial de la arquitectura moderna en Brasil; para el arquitecto brasileño Fernando Tábora, colaborador de Burle Marx, el avance que representó el jardín del Ministerio fue similar al que en esos años se produjo en la arquitectura brasileña: "Roberto tenía, por sus estudios de pintura, un conocimiento muy profundo de la historia de los jardines y de las experiencias en ese campo en Brasil. Su salto evolutivo del clasicismo de Pernambuco a las "amebas" del Ministerio equivale a los mismos pasos dados por los arquitectos de la época, como Lucio Costa en Brasil y Villanueva en Venezuela" (Oliveira 2001). 
Figura 7. Le

Corbusier. Vista del jardin de la terraza del ministro (Le Corbusier, 1975).

Figura 8. R. Burle Marx. Primera propuesta para el jardin de la terraza del Ministerio de Educación (Dourado, 2009).

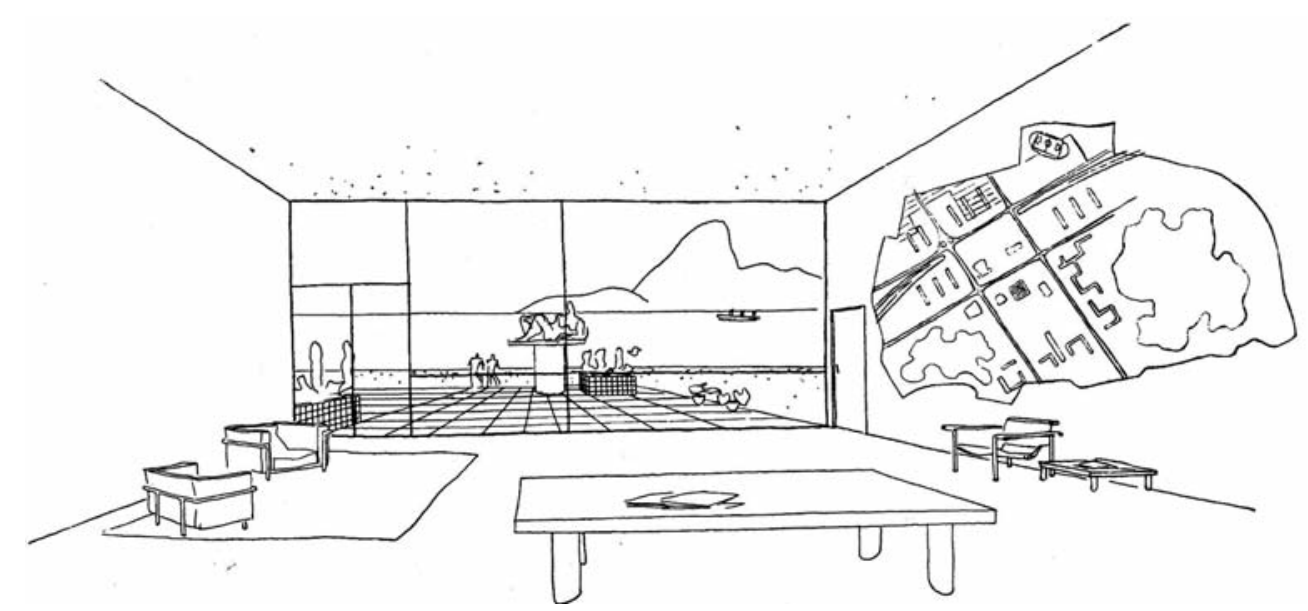

En 1935 se había celebrado un concurso para la construcción del nuevo edificio del Ministerio, supervisado personalmente por el ministro Gustavo Capanema. El proyecto ganador de corte academicista, obra de los arquitectos Archimedes Memória y Francisque Cuchet, no era del agrado del ministro, que encargó un nuevo proyecto a Lucio Costa, dirigiendo un equipo de jóvenes arquitectos: Affonso Eduardo Reidy, Jorge Moreira, Oscar Niemeyer, Carlos Leao y Ernani Vasconcelos, todos ellos convencidos seguidores de Le Corbusier. Con objeto de acallar las voces anti-moder-
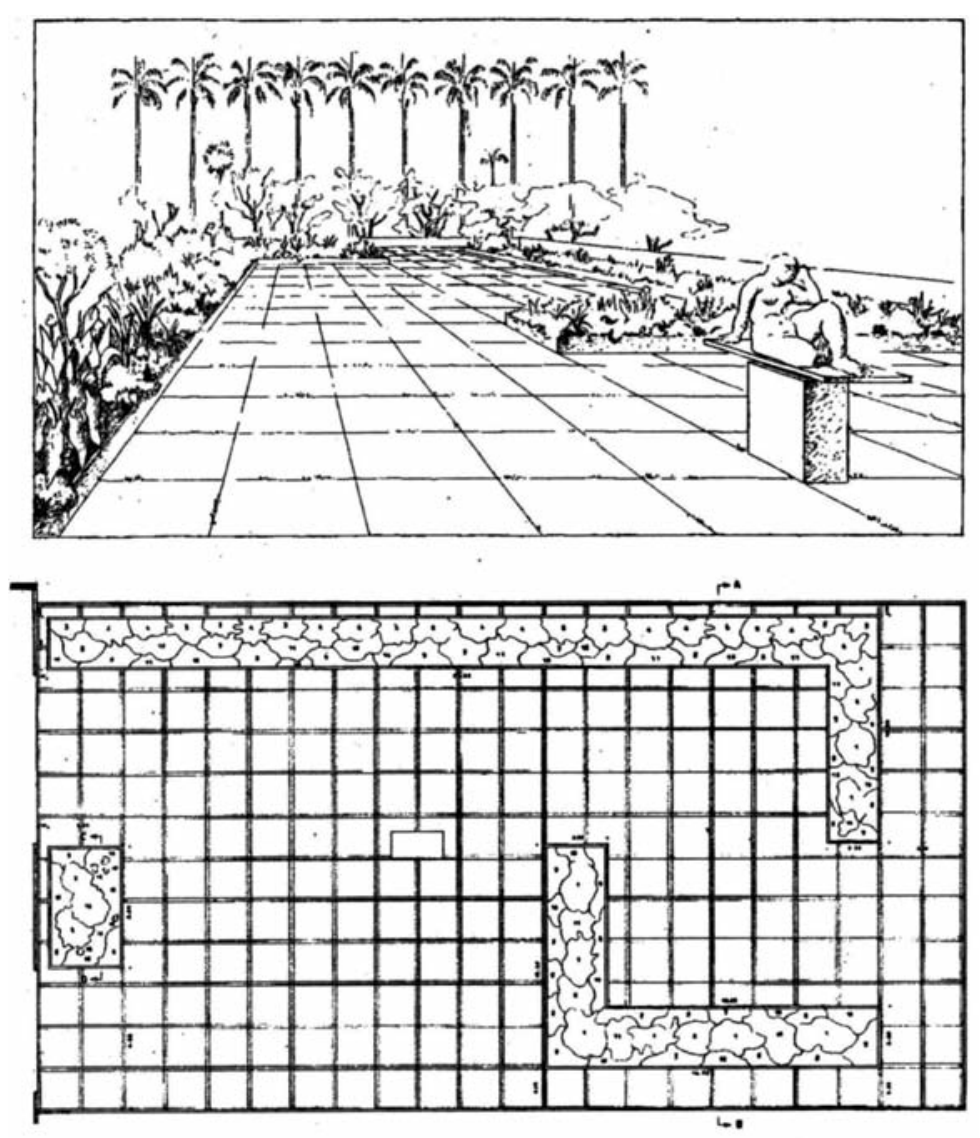

nas que tachaban de comunistas a los miembros del equipo, el propio Lucio Costa inició las gestiones para lograr que el ministro invitase a Le Corbusier a viajar a Brasil para actuar como consultor del proyecto $^{3}$. Le Corbusier, en las cartas que intercambió con Costa previamente al viaje, insistía en encargarse directamente de la redacción del proyecto, pero la legislación de Brasil, entonces bajo la dictadura de Getulio Vargas, impedía el trabajo de arquitectos e ingenieros extranjeros para evitar la entrada en el país de ideas foráneas. Finalmente, Le Corbusier viajó a Brasil en julio de 1936 a bordo del zeppelín Hindemburg y permaneció algo más de un mes, dictando seis conferencias y trabajando con el equipo de Costa en los proyectos del Ministerio y de la Ciudad Universitaria. ${ }^{4}$

Durante su estancia, Le Corbusier realizó con el equipo brasileño dos propuestas diferentes para el Ministerio, que sirvieron de guía para el proyecto definitivo, sólo concretado tiempo después de la vuelta del arquitecto a París, bajo el impulso de Niemeyer, como le contaría más tarde el propio Costa a Le Corbusier. El proyecto del equipo partía de un cumplimiento estricto de los cinco puntos de Le Corbusier, incluyendo el toit-jardin; así planteaban un jardin en la cubierta del bloque central y otro en la cubierta del auditorio, orientado hacia la bahía de Guanabara, pensado para ser visto desde la biblioteca del cuarto piso, para mayor deleite de los lectores. Le Corbusier reforzó esta idea al concebir un nuevo jardín para la terraza del ministro, como continuación visual del despacho, resuelto mediante jardineras geométricas, junto con una gran escultura, como contrapunto a la ondulación plástica de los característicos morros (elevaciones montañosas) del paisaje de Río. Las formas del jardin recuerdan a las del Apartamento Beistegui o de la Ciudad 
Figura 9. Gertrude Jekyll. Diseño de un macizo para un jardín de Edwin Lutyens (Brown, 1994).

Figura 10. R. Burle Marx. Jardin de la terraza del Ministerio de Educación, planta (gouache sobre cartón), 1938 (Adams, 1991).

Figura 11. Planta $3^{a}$ del Ministerio de Educación. Estado intermedio y estado final de la planta del despacho del ministro (1. Despacho del ministro, 2. Secretario, 3. Despachos). El dibujo del estado intermedio del jardin podria deberse a Oscar Niemeyer. (Botey, José M. 1996. Oscar Niemeyer. Barcelona: Gustavo Gili; Mindlin, Henrique E. 2000. Arquitetura moderna no Brasil. Río de Janeiro: IPHAN).
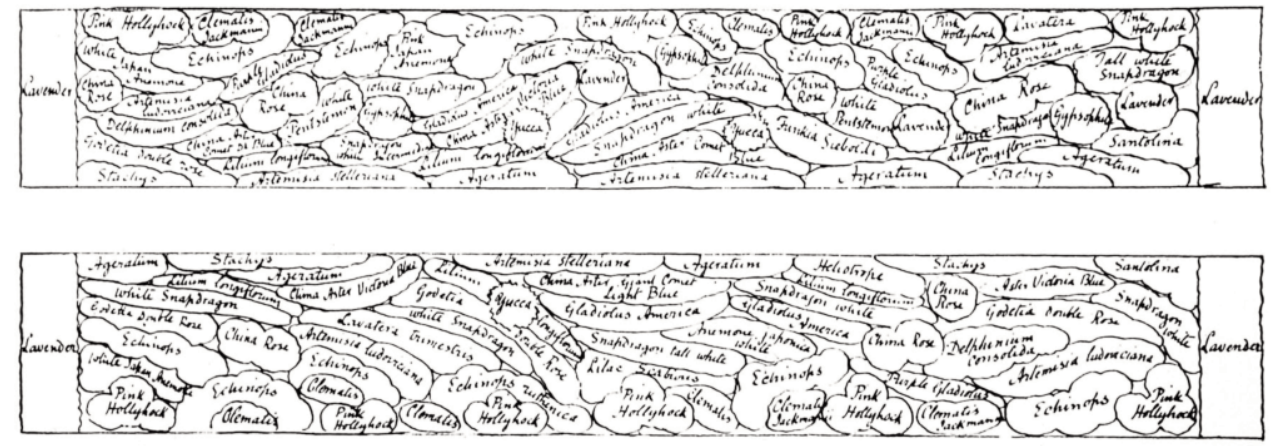

Refugio para el Ejército de Salvación, ambos realizados por el arquitecto en París en la década de 1930.

Tras la marcha de Le Corbusier, Burle Marx, que había comenzado participando en la obra como ayudante de Cándido Portinari en la elaboración de los murales cerámicos del edificio, se hizo cargo, por expreso deseo de Lucio Costa, del diseño
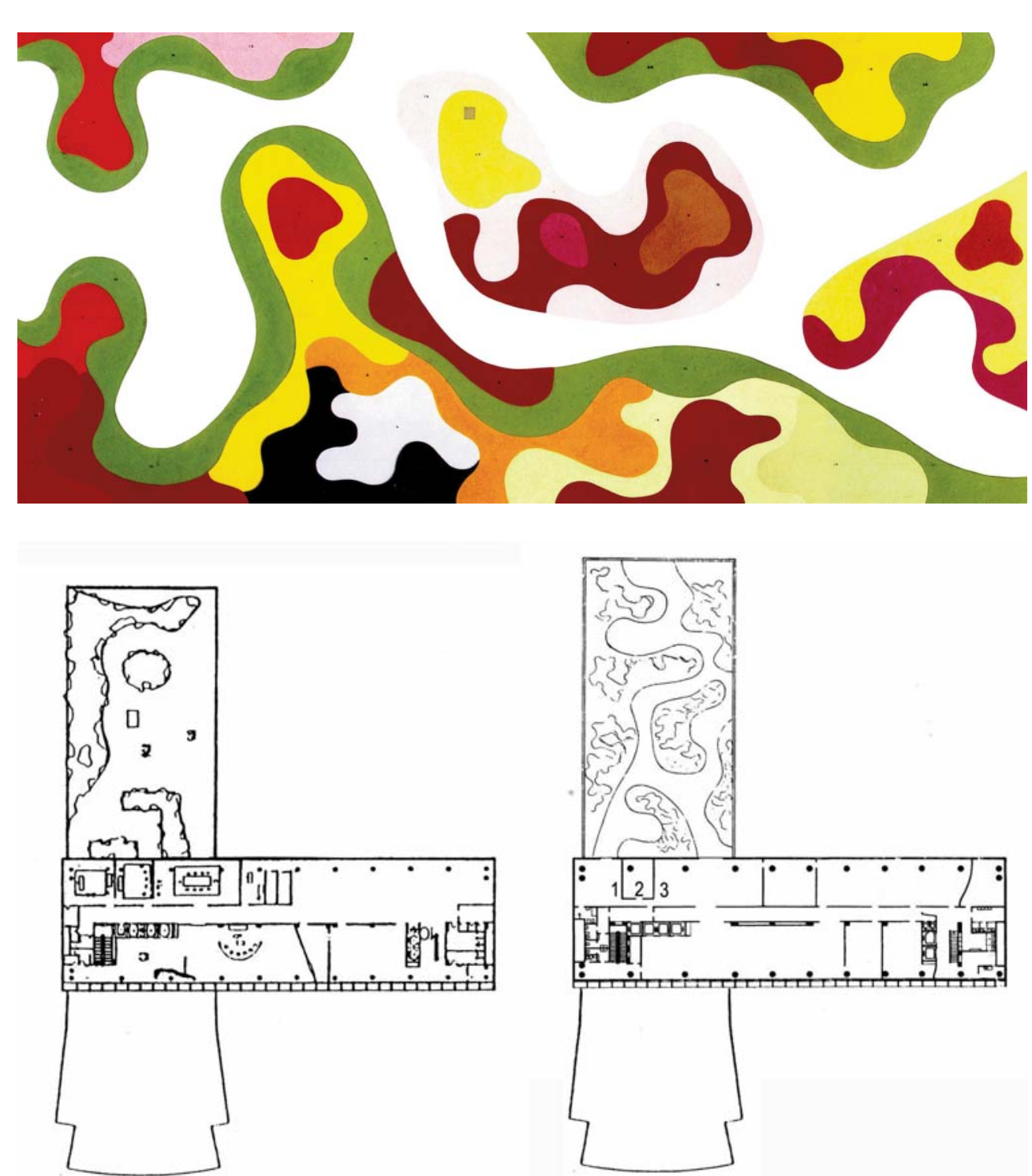

de los tres jardines del Ministerio, el de la plaza, el de la cubierta y el de la terraza del ministro ${ }^{5}$. Su primera propuesta para el jardín de la terraza se realizó en clave geométrica, siguiendo la idea inicial de Le Corbusier; la planta se limitaba a una pavimentación regular con una escultura levantada sobre un pedestal y dos jardineras en $\mathrm{L}$ con plantaciones formando un mosaico vegetal irregular, un procedimien-

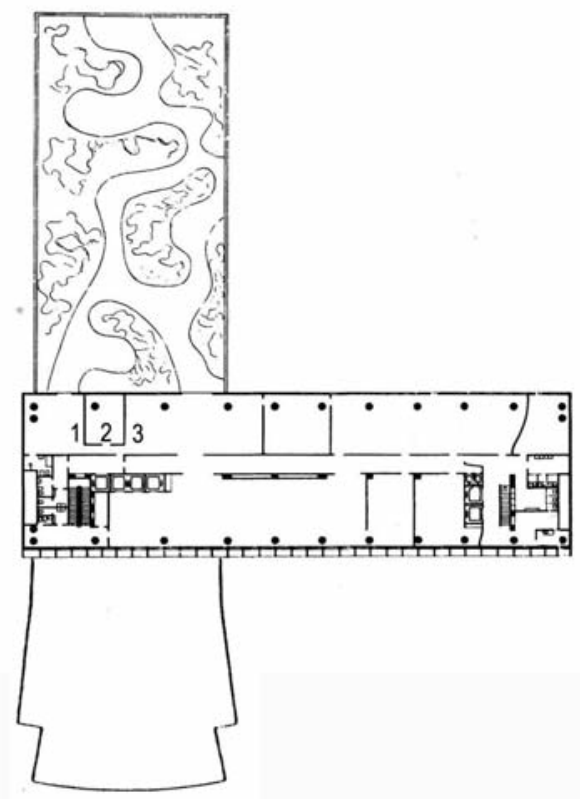




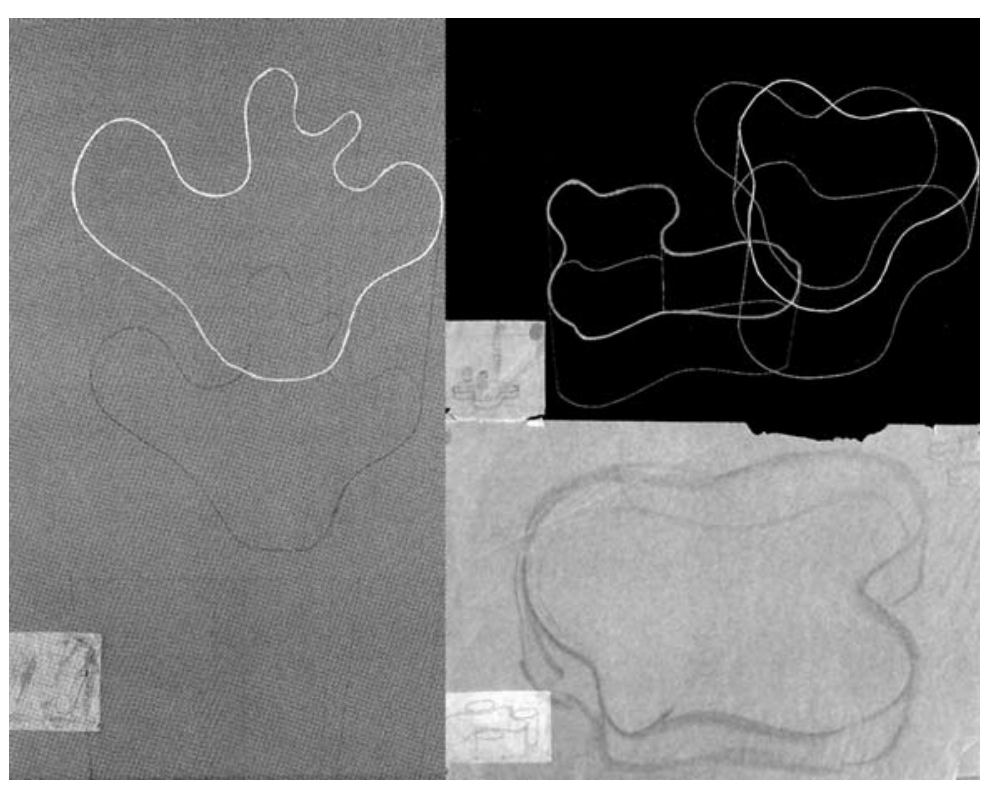

Figura

12. Alvar Aalto.

Diseño de los jarrones Savoy, Helsinki, 1936 (Jové Sandoval, 2003). to similar al utilizado por Gertrude Jekyll en los jardines de Edwin Lutyens.

Sin embargo, Burle Marx abandonó este planteamiento inicial y realizó una sorprendente propuesta para el jardin, plasmada en un gouache sobre cartón (fechado en 1938), que desarrolla unas formas orgánicas, cuidadosamente elaboradas, sobre el rectángulo de la terraza, con un fuerte cromatismo en el que predominan los tonos cálidos que van desde el verde base hasta el rojo, en una composición equilibrada y a la vez dinámica y vibrante que constituyó una auténtica revolución estilística en la historia del paisaje. Resulta dificil imaginar qué pasó por la cabeza del artista para dar un giro tan radical a su proyecto y concebir esta extraordinaria representación, dando forma a uno de los paradigmas del jardin moderno: se liberó de la geometría y de toda atadura funcional y constructiva $\mathrm{y}$ experimentó con la forma y el color, iniciando asi una línea de trabajo totalmente innovadora y personal, añadiendo una nueva impronta al proyecto del edificio.

Las formas que Burle Marx utilizó en la composición del jardín del Ministerio acabarian contaminando gran parte de la producción arquitectónica moderna brasileña, especialmente la obra de Oscar Niemeyer, pero en aquel momento resultaban novedosas y atrevidas, aunque cabe reseñar que al mismo tiempo, en el otro extremo del mundo, Alvar Aalto estaba proyectando la Villa Mairea que incorporaba formas orgánicas, especialmente en el paisaje del jardín con la piscina, y que dos años antes había realizado los diseños para la serie de jarrones Savoy, como expresión congelada en vidrio del paisaje finlandés.

\section{Un paisaje moderno}

Para el arquitecto y teórico italiano Bruno Zevi, las formas orgánicas del jardin del Ministerio eran una "forma de compensación psicológica" de difícil equilibrio entre lo regular y lo irregular, "reconcilian la forma pura de la geometría racionalista con las curvas de la lujuriosa naturaleza tropical" (Montero 2001). Aunque el propio Burle Marx afirmó que ya había utilizado formas curvas en alguno de los proyectos de Recife, sólo en el diseño de la plaza Arthur Oscar en Recife encontramos un gesto parecido en la distribución de las plantas dentro de una gran jardinera circular, pero sin el grado de autonomía formal y $\sin$ la riqueza compositiva que alcanzaba el jardin del Ministerio.
Figura 13. Campo de Santa Ana, A. F. M. Glaziou, Río de Janeiro, 1873-1880. (Adams, 1991).

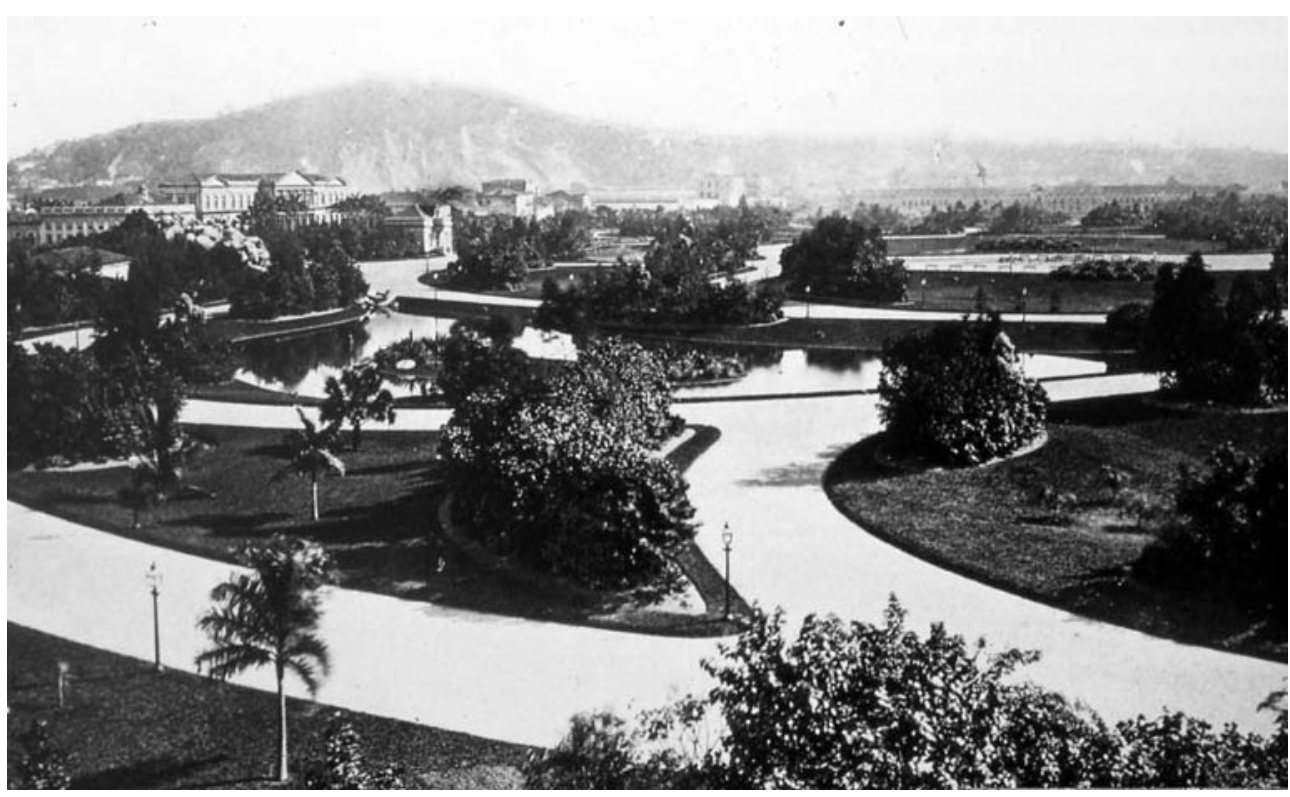




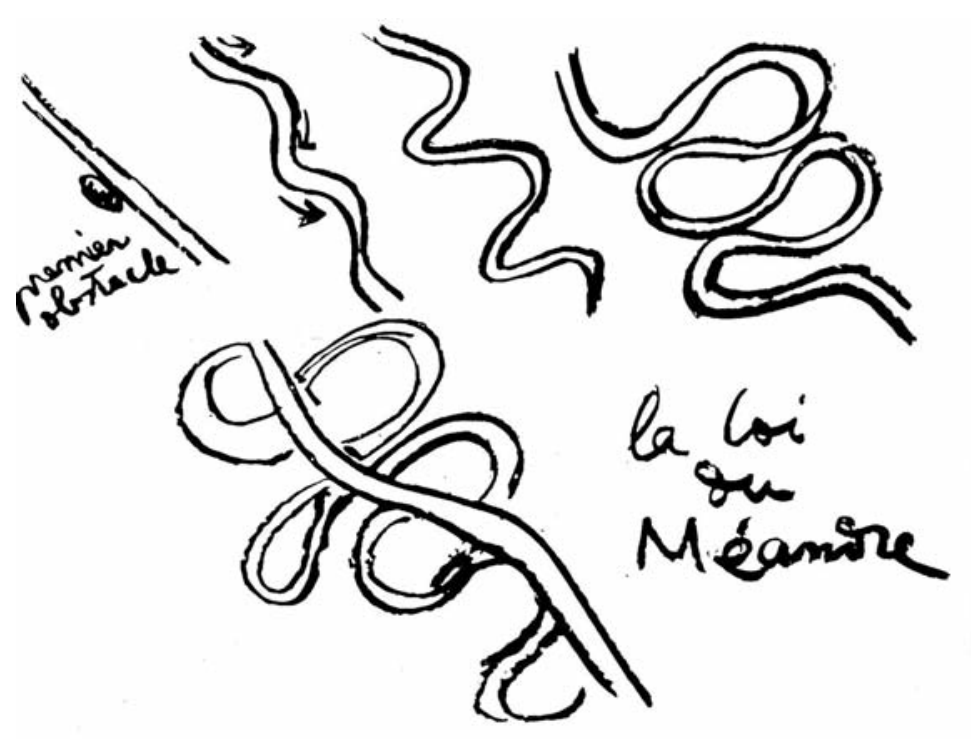

Figura 14. Le Corbusier, "Ley del meandro" (Le Corbusier, 1999).

Figura 15. Le Corbusier. Cubiertajardin en los bloques de la Ville Radieuse (Le Corbusier, 1975).
Algunos autores, como W.H. Adams (1991), han visto en el jardín del Ministerio influencias directas de las elaboradas curvas del Campo de Santa Ana, un parque construido en Río de Janeiro entre 1873 y 1880 por Auguste François M. Glaziou, ingeniero francés que había colaborado en la oficina de Adolphe Alphand en la realización de los parques de París durante el Segundo Imperio. Otros han intentado explicar el jardín como una reinterpretación del jardín inglés, pero el propio Burle Marx encontraba una gran diferencia entre su arte y el de los paisajistas ingleses del XVIII: "la mayor diferencia con los antiguos paisajistas se basa en la capacidad de usar el color en el jardín, una de las cosas más dificiles. Es necesario buscarla en las grandes pinturas de este siglo, en la obra de Braque o de Picasso, en los impresionistas, en Van Gogh o en Gauguin" (Tabacow 2004: 62). En efecto, los diseñadores de jardines ingleses (entre ellos el arquitecto William Kent o el paisajista Lancelot Brown) abandonaron prácticamente el uso del color en sus composiciones, y confiaron, fundamentalmente, en el poder visual de las grandes manchas verdes de las praderas, recortadas por los perfiles brillantes de los lagos, con algunos añadidos arquitectónicos. Según Burle Marx, la pintura moderna aportó un material novedoso, el color, que amplió notablemente la paleta del diseñador de jardines. Además observó una limitación importante de los paisajistas ingleses al utilizar un escaso número de especies vegetales: "Capability Brown plantó, en una ocasión, cerca de cuatrocientos mil metros cuadrados con apenas ocho especies de árboles, obteniendo de ellos el mayor efecto; y trabajó siempre con árboles nativos de las Islas Británicas, un número de especies verdaderamente reducido" (Tabacow 2004: 62); para el paisajista brasileño, un repertorio vegetal más amplio no sólo daba variedad formal a la composición sino, sobre todo, amplitud cromática, redundando en el argumento anterior.

La suma de los conocimientos de ambas disciplinas, jardinería y pintura, fue la clave de los felices hallazgos formales, compositivos y visuales de Burle Marx, como él mismo manifestaria: "Detesto esa idea de que el paisajista sólo debe conocer plantas. Tiene que saber qué es un Piero de la Francesca, y comprender un Miró, un Miguel Ángel, un Picasso, un Braque, un Léger, un Karl Hofer, un Renoir, un Delaunay" (Oliveira 2007).

Se ha leído el jardín del Ministerio como una topografia inspirada en las formas típicas de la selva tropical brasileña: un río con meandros en torno al cual se despliegan manchas exuberantes de vegetación

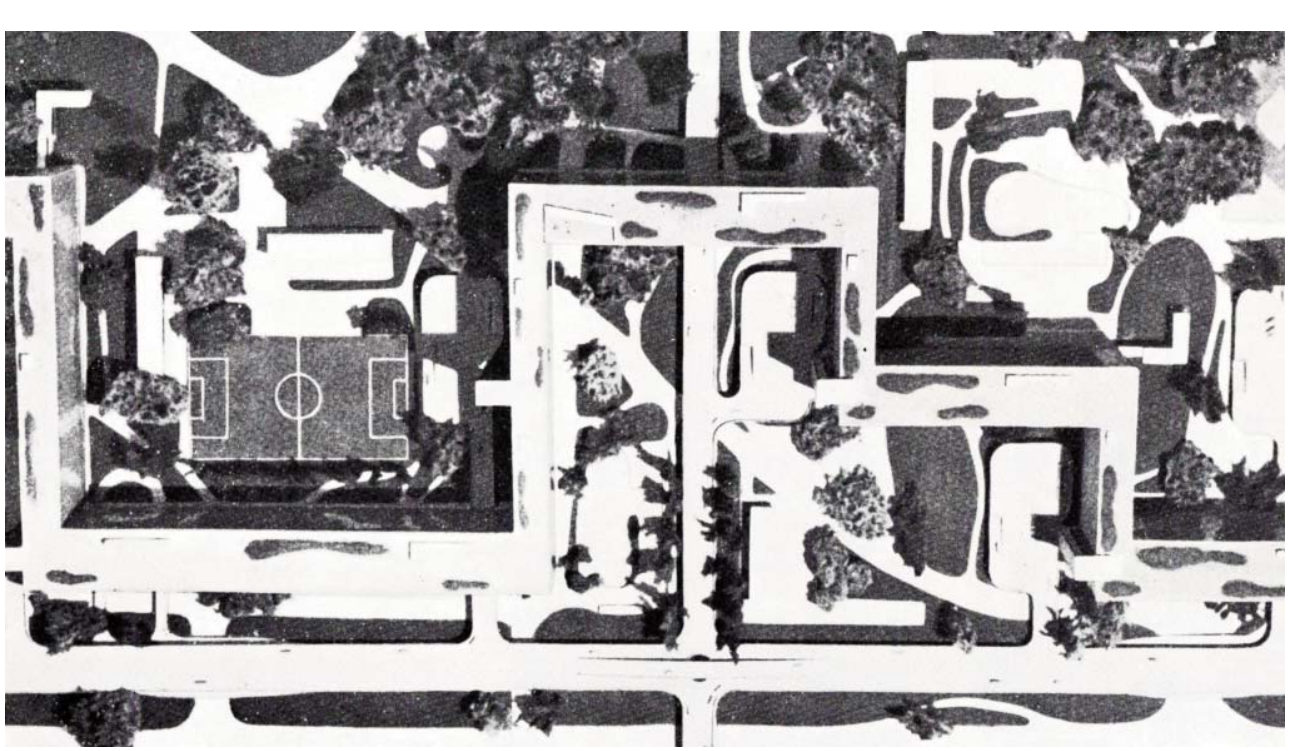




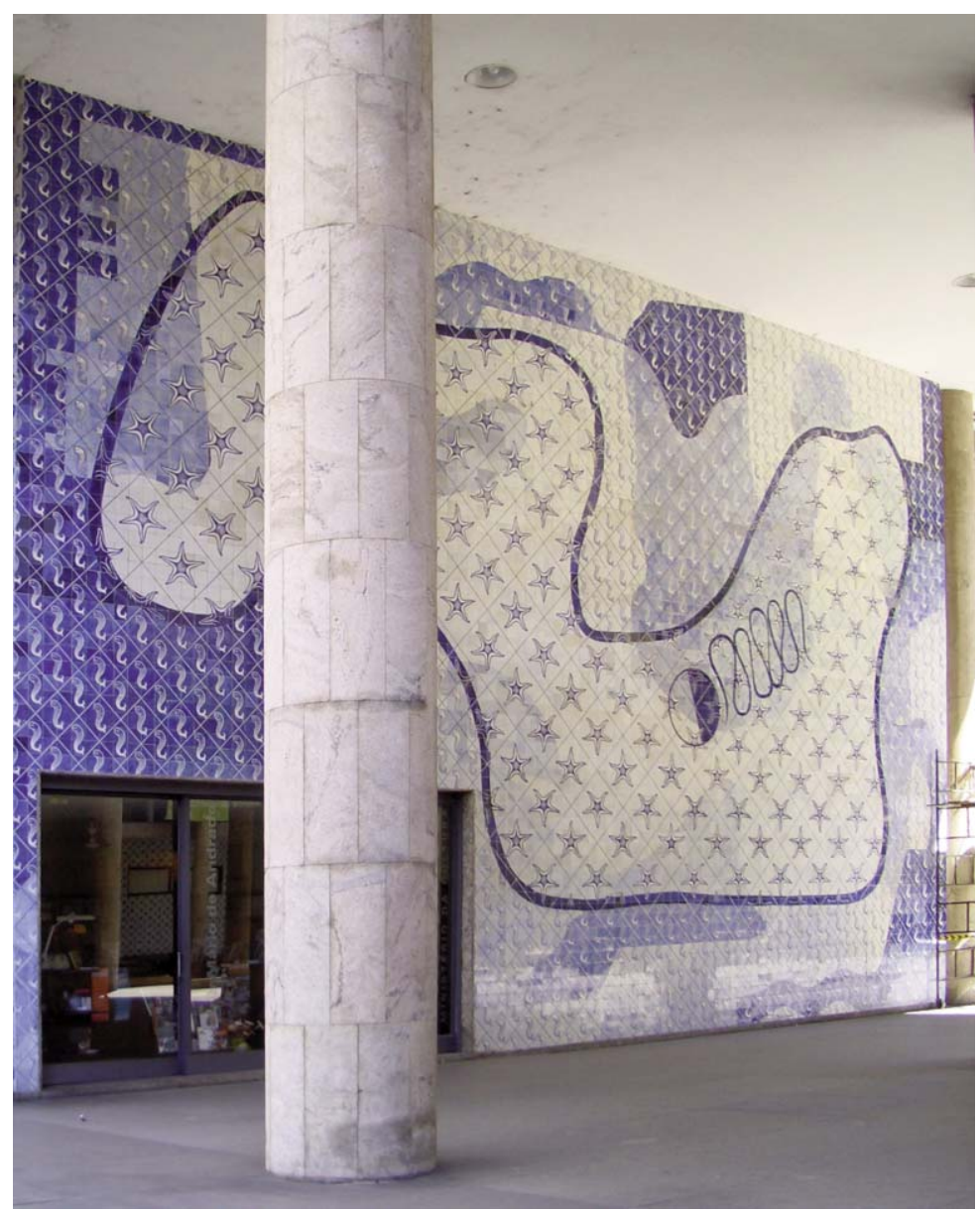

Figura 16. Mural cerámico de Cándido Portinari (con la colaboración de R. Burle Marx) en la planta baja del Ministerio de Educación. (Fotografia: R. R. Llera).

Figura 17. Jean Arp, "Configuración", relieve, 1933 (Arp, 2006). de todos los colores. A partir de esta idea, Valerie Fraser (2000) propone una analogía entre las formas del jardín y la "ley del meandro", enunciada por Le Corbusier en una de las conferencias impartidas en Buenos Aires en octubre de 1929 y recogida posteriormente en 1930 en su libro Precisiones. La "ley del meandro" surge, como él mismo explica, de las visiones aéreas de los grandes ríos sudamericanos, en especial el Amazonas:

La analogía propuesta por Fraser resulta interesante: las curvas de Burle Marx serían el resultado de un "canibalismo" intelectual del pensamiento de Le Corbusier. Este concepto del "canibalismo" surge directamente del célebre Manifiesto Antropófago que el poeta Oswaldo de Andrade habia publicado en 1928 sobre la capacidad de la cultura brasileña para devorar la historia y la cultura europeas y hacerlas suyas; la idea de "antropofagia" revolucionó el pensamiento en Brasil, convirtiéndose directamente en una particular vanguardia introductora de la modernidad en el país.

Roberto Burle Marx sintió, como otros muchos artistas y arquitectos brasileños, una especial atracción por la obra de le Corbusier, como ya había evidenciado en el jardín de la Casa Schwartz: "Un amigo me trajo una serie de libros de Le Corbusier: Vers une architecture, Une maison, un palais, L'Art décoratif d'aujourd'hui. Al leerlos se fue abriendo mi visión. Le Corbusier estuvo aquí, fue siempre una figura extraordinaria, con un pensamiento nítido y claro. Basta coger, por ejemplo, su libro Vers une architecture, en donde consigue hablar sobre arte con una claridad impresionante" (Oliveira 2007). Además de la referencia a la "ley del meandro" cabría señalar que el mismo Le Corbusier había propuesto a principios de la década de 1930 formas orgánicas en los jardines de las cubiertas de los bloques à redent de la Ville Radieuse, que podríamos considerar el origen de la experimentación de Burle Marx, pero la referencia resulta insuficiente para explicar al completo el hallazgo formal que supuso el jardín del Ministerio.

\section{Jean Arp}

Las formas curvas del jardin del Ministerio diseñado/pintado por Burle Marx están más construidas que los meandros o los macizos ondulados dibujados por Le Corbusier y poseen una mayor intensidad formal. Encontramos un cierto paralelismo entre las formas del jardín y las de los revestimientos cerámicos de Portinari para el Ministerio6, plagados de referencias marinas (ondas, cangrejos, caballitos de mar), pero según el propio Burle Marx la clave se encuentra en la obra de Jean Arp: "Hice el jardin del Ministerio con unas manchas bastante abstractas porque en esa época ya conocía a Arp" (Oliveira 2007).

En numerosas ocasiones, con motivo de conferencias o entrevistas, Burle Marx se refirió a la influencia que había ejercido en él la obra de pintores como Van Gogh, Matisse, Braque y Picasso, pero sólo en esa ocasión aludió a Jean Arp de manera tan lacónica como precisa. Esta afirmación

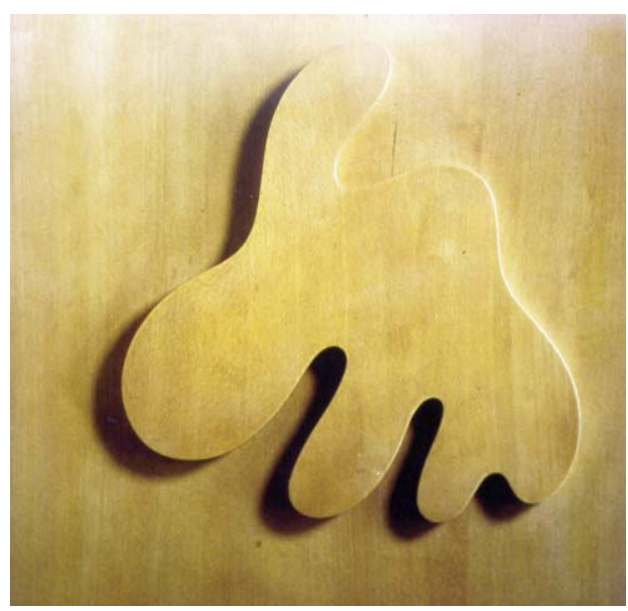


nos permite pensar que las composiciones de Arp pasaron, en las manos de Burle Marx, del plano del cuadro o del relieve al suelo del jardín, generando un inusitado paisaje biomórfico en clave totalmente surrealista. ${ }^{7}$

Jean Arp, quien ejerció una gran influencia sobre Joan Miró, no fue un artista plenamente abstracto, sus formas sugieren siempre veladas alusiones a elementos de la naturaleza -flor, bosque, constelación-, aunque sus composiciones, como las del propio Burle Marx, nunca reproducen literalmente escenas naturales: "No pretendo copiar la naturaleza. No quiero reproducirla" (Arp 2006: 151) diría el artista suizo. La relación con la naturaleza es similar en ambos autores; lejos de imitarla, creando "sucedáneos", planteaban una visión crítica que ayudase a una mejor comprensión de los conceptos artísticos: "Recuerdo que discutiendo con Mondrian, él oponía el arte a la naturaleza diciendo que el arte es artificial y la naturaleza natural. No comparto su opinión. Pienso que la naturaleza no se opone al arte. El arte es de origen natural y se sublima y se espiritualiza con la sublimación del hombre." (Arp 2006: 161).

El collage de madera, en forma de relieve, a medio camino entre la pintura y la escultura, fue para Arp un magnífico medio de expresión, ya que sugería la posibilidad de nuevos caminos en la creación: "Proseguí desarrollando la técnica del collage, rechazando la voluntad de la composición y entregándome a una ejecución automática. Lo llamé "trabajar según las leyes del azar", la ley que contiene a todas las demás y que no llegamos a comprender, como tampoco comprendemos la causa primigenia que hace brotar cualquier tipo de vida y que sólo puede experimentarse mediante una total entrega al inconsciente. Yo sostenía que quien obedeciese esta

Figura 18. Jean Arp, "Tres formas blancas estrellándose sobre fondo gris", óleo sobre madera, 1930 (Arp, 2006). ley crearía la vida en estado puro" (Arp 1966). Esta afirmación podría aplicarse también a la técnica de Burle Marx, aunque obviando parcialmente el concepto del automatismo.

Si analizamos detalladamente la "planta pintada" original del jardín del Ministerio podemos descubrir como Burle Marx realiza un cuidadoso proceso de superposición de capas o estratos: la base es algo parecido, en efecto, a un curso de agua ondulante, al cual se van añadiendo formas topográficas dotadas de una gran lógica constructiva; el resultado es un paisaje que bebe tanto de las formas naturales como de las formas plásticas. Finalizada la operación compositiva el artista dota de color a esos estratos abstractos configurando un paisaje-collage de gran luminosidad y un cierto efecto dramático, un verdadero proceso de proyecto realizado a partir de materiales pictóricos. La sustitución de estos planos por superficies vegetales, con su cromatismo y volumen correspondiente, hecho de gran trascendencia en el resultado final, dan como resultado el espacio real del jardín. Este proceso le da al jardín un sentido material que lo separa de la pintura pura y que lo acerca, notablemente, a la arquitectura. De esta manera el jardín compone un paisaje, con evidentes alusiones tropicales, pero reinterpretado a la luz de las formas abstractas surrealistas de Arp, y construido con los elementos vegetales de la naturaleza original, un complejo proceso de abstracción y concreción, que resulta sumamente interesante. Podemos concluir que Burle Marx reinventa una naturaleza en clave surrealista y la hace suya convertida en objeto plástico producto de un complejo proceso que va de lo real a lo onirico mediante el sabio manejo de la forma y del color.

Sin embargo, debemos mencionar aquí el hecho de que el camino del surrealismo tropicalista seguido por Burle Marx había sido previamente preparado con gran acierto y éxito por la artista brasileña Tarsila do Amaral, que unos años antes había desarrollado su particular visión del discurso de la "antropofagia" de su marido, el poeta Oswald de Andrade, pintando paisajes biomórficos que necesariamente formaban parte del bagaje cultural del paisajista, a quien la pintora tenía en muy alta consideración, llegando a llamarle en 1936 "poeta de los jardines": "tiene vocación para la música, la pintura, la escultura, el teatro, es decir: para cualquier arte; tiene el don de conocer y hablar diversos idiomas, tiene la paciencia del investigador, la memoria para guardar el nombre científico 

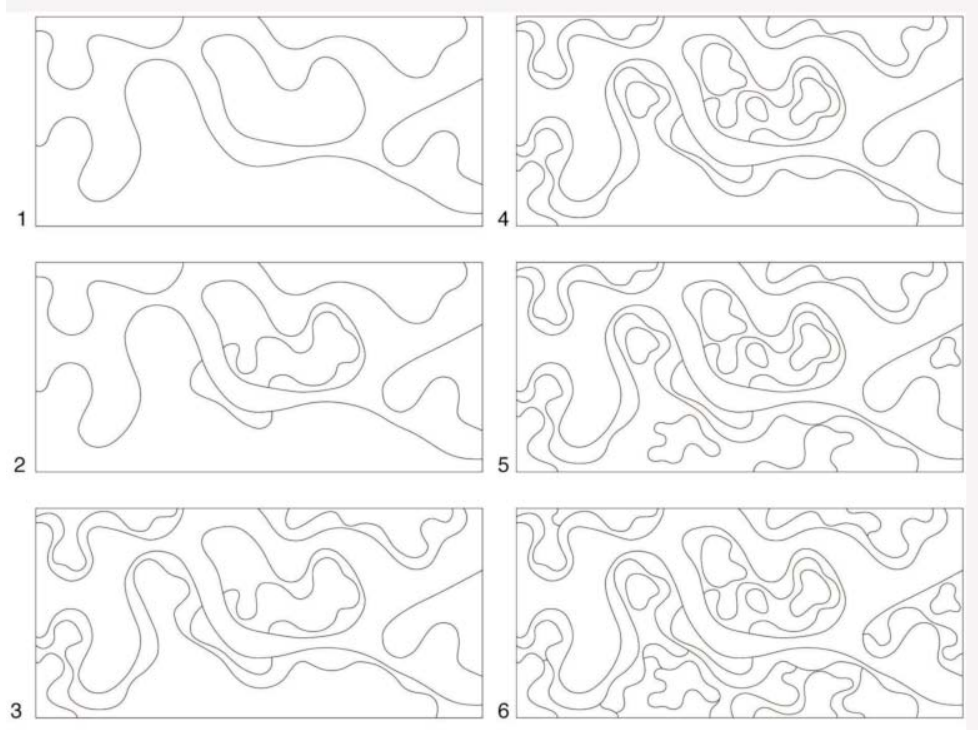

Figura 19. Jardin de la terraza del Ministerio de Educación. Secuencia compositiva del jardin. Dibujo del autor.

Figura 20. Tarsila do Amaral. El lago, 1928 (Amaral, 2009).

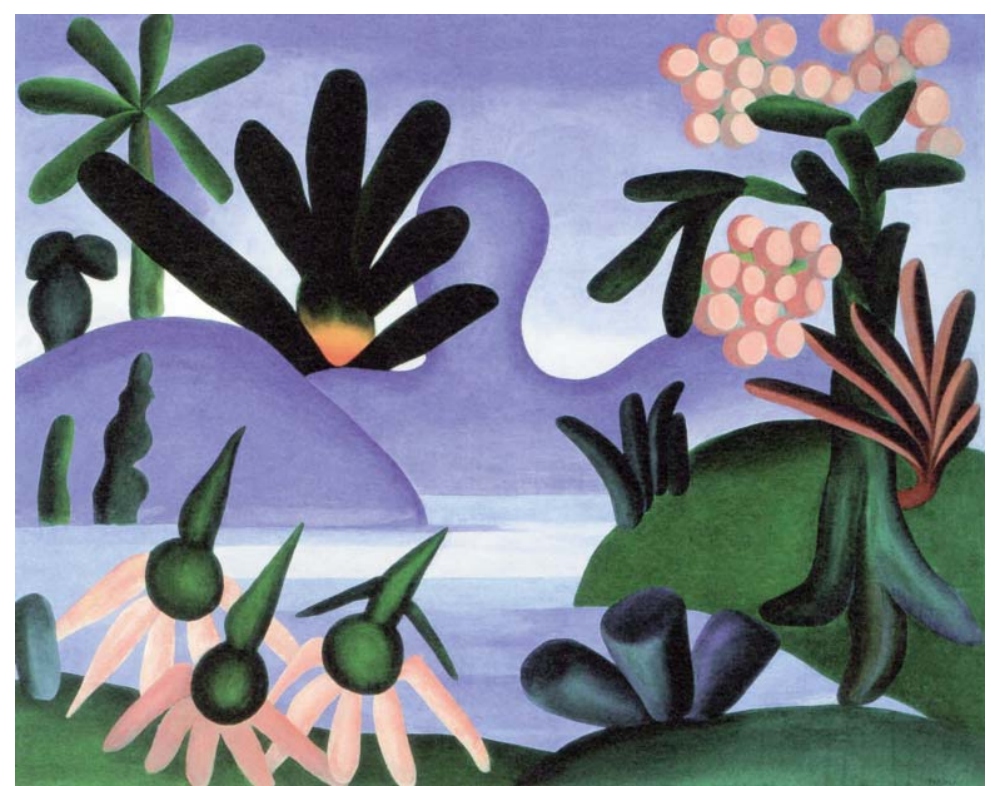
vida es limitada: se afirmó en la pintura y el arte de construir jardines; el arte de ordenar los caprichos y los imprevistos de la naturaleza y de adaptarlos a formas y bellos diseños, sugeridos por esos mismos imprevistos" (Amaral 2009: 214).

La biografia de Burle Marx plantea grandes contradicciones en su relación entre jardin y pintura. En algunos momentos afirmó que existía una identidad entre su pintura y sus jardines, sin distinción, como manifestaciones de una misma idea, realizadas con materiales diferentes: "Como artista plástico he recibido una formación rigurosa en las disciplinas de dibujo y pintura, y mi idea de jardin es el resultado de una sedimentación de circunstancias. He aplicado a la naturaleza los prin- cipios de la composición plástica, según el sentimiento estético de mi época. El jardin, finalmente, ha sido una manera de organizar y de componer mis obras pictóricas utilizando materiales no convencionales. En parte, puedo explicar esta evolución por el efecto que produjeron en mi generación el cubismo y el arte abstracto" (Tabacow 2004: 23).

En algunos momentos sus afirmaciones no dejan ningún asomo de duda: "no diferencio entre el objeto "pintura" y el objeto "paisaje" que construyo. Sólo cambian los medios de expresión" (Tabacow 2004: 23). Sin embargo, en otros, se expresó de forma bien diferente: "Es una gran estupidez confundir mis jardines con pintura. Cada modalidad artística tiene una manera propia de expresarse. Por ejemplo, el color en la pintura es mucho más preciso que en el jardin. En el jardin, el color cambia con la hora del día, con la luz. Un cuadro en la oscuridad es diferente de un cuadro con iluminación diferente" (Oliveira 2007).

\section{Tiempo y jardin}

Llegados a este punto podemos preguntarnos cuál de las dos visiones de Burle Marx es la cierta; probablemente las dos, si queremos entender en profundidad sus afirmaciones contrapuestas. Su jardín es pintura y al mismo tiempo no lo es; este es el argumento, aparentemente contradictorio, que manejaba el artista brasileño. Las razones básicas de esa diferencia son la dimensión, el movimiento y, sobre todo, el concepto del tiempo. Para Burle Marx "la gran diferencia entre el pintor bidimensional y el paisajista tridimensional es que la planta -la materia prima- no es estática". En sus propias palabras, el jardín y la pintura son dos "objetos" de similares características, lo que no quiere decir que sean exactamente lo mismo, ahí radicaría la esencia de la aparente contradicción argumental. Burle Marx puede pensar "sus formas" básicas como "formas pictóricas", pero el desarrollo es bien diferente si se trata de pintura pura o de jardín, ahí la cosa cambia de manera sustancial, porque en el jardín se introduce la tridimensionalidad, la luz y también el movimiento: en el cuadro el movimiento es experiencia puramente visual del espectador, en el jardín el movimiento se hace real. Podemos afirmar que a Burle Marx no le basta la experimentación plana de la pintura, ni siquiera la tridimensional de la escultura, necesita la experiencia vital del espacio, algo que solo puede acontecer en la arquitectura y en el jardín, configurado básicamente con elementos dinámicos vegetales, construido con el tiempo como materia. En la pintura 
Figura 21. W. Kandinsky. Curva geométricamente ondulada (Kandinsky 1926).

Centro. Figura 22, abajo. Jardin del Ministerio de

Educación. Vista del jardin desde el despacho del ministro. Montaje del autor.

Abajo izquierda. Figura 24. Jardin del Ministerio de Educación, vista del estado original en la década de 1940. (Adams, 1991).

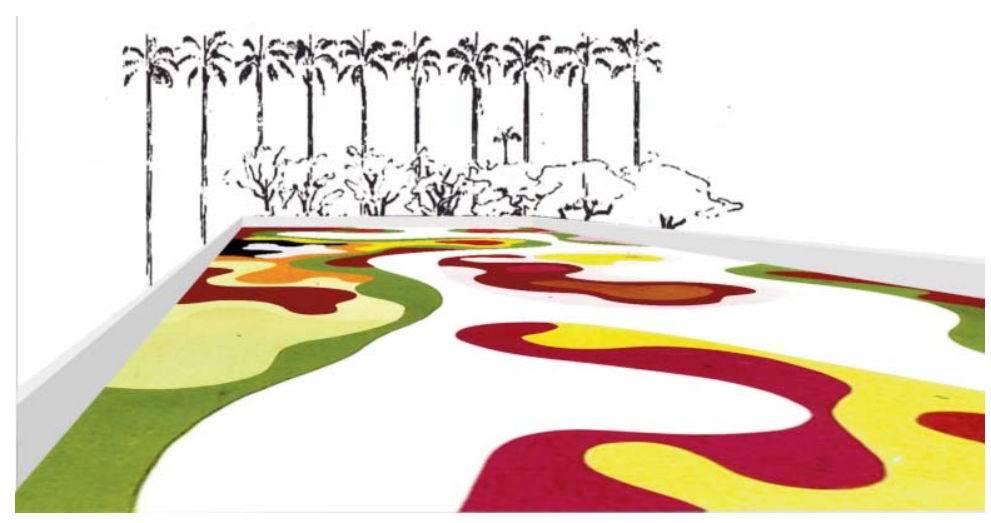

Abajo derecha. Figura 23. Interior del Ministerio de Educación. Vista de la antesala del despacho del Ministro en planta $3^{a}$ con el mostrador $y$ la alfombra ondulados (ref. web 2).

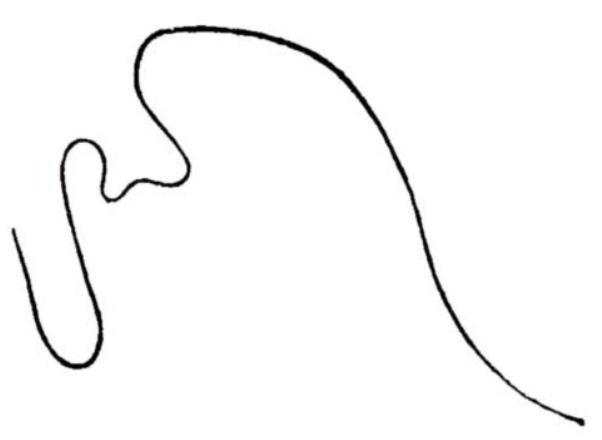

el tiempo permanece congelado, mientras que el jardín es pura representación del tiempo en desarrollo: el tiempo del dia, con sus variaciones de luz, el tiempo de las estaciones, con los cambios formales y cro- máticos de la vegetación, $\mathrm{y}$, finalmente, propio tiempo del espectador que se desplaza visual y fisicamente por el jardín, creando así una compleja superposición de tiempos que enriquece notablemente la experiencia del espacio.

Conviene introducir aquí una nueva referencia en la elaboración de las formas de

paisaje de Burle Marx, la linea ondulada sistematizada por Kandinsky en su libro Punto y línea sobre el plano, publicado en 1926, resultante de tensiones vinculadas con el tiempo y el movimiento. Kandinsky define la "curva complicada u ondulada", como la "suma de arcos de círculo geométrico, o de segmentos libres, o de diferentes combinaciones de ambos"8, diferenciando entre "curva geométricamente ondulada" y "curva libremente ondulada"; uno de los ejemplos que ilustran este segundo grupo parece coincidir plenamente con las curvas de Burle Marx: "Curva libremente ondulada: se acrecientan los desplazamientos. Lucha temperamental entre las dos fuerzas. La presión positiva empuja hacia una altura muy elevada" (Kandinsky 1926).

Si volvemos al jardín del Ministerio encontramos esta "lucha de tensiones" no tanto en la planta ni en la vista desde la cubierta sino en la visión desde el despacho del ministro, 9 acentuadas las ondulaciones por la deformación del escorzo, intensificando el movimiento y la concepción del tiempo, que se desplaza de manera vertiginosa por el jardín, solo detenido por las palmeras imperiales que bordean la plaza, un residuo de las imágenes iniciales propuestas por Le Corbusier. Sensaciones similares encontramos también en el interior, en la gran sala con el mural pintado por Portinari, en el mostrador curvo y, sobre todo, en la alfombra biomórfica, diseñada por Burle Marx y Niemeyer como un genial y acertado trasunto del jardín exterior en el interior del edificio.

El jardin del Ministerio se realizó según el diseño de Burle Marx, completando la composición plana con los volúmenes y los colores aportados la vegetación, como
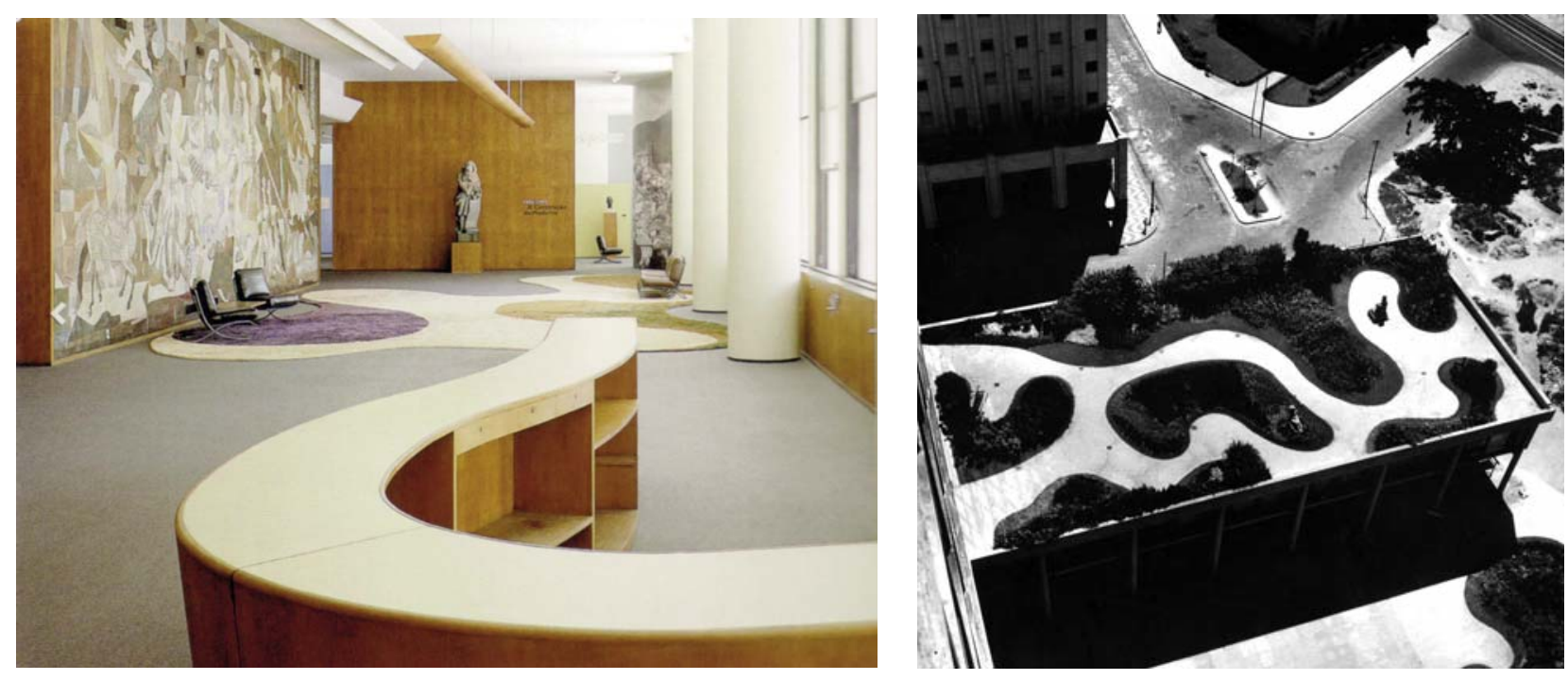

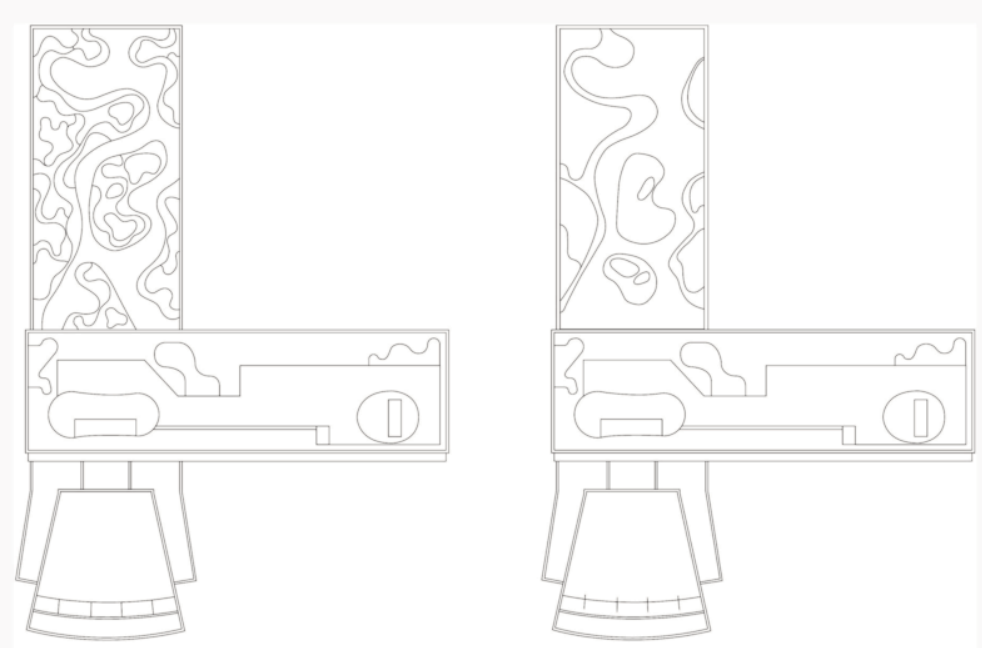

Figura 25. Jardin del Ministerio de

Educación, estado original y estado actual. Dibujo del autor.

Figura 26. Jardin del Ministerio de Educación (Fotografia: R. R. Llera).

Figura 27. Jardines de la terraza y de la plaza del Ministerio de Educación (Fotografia: R. R. Llera). podemos apreciar en las pocas fotografias de la época, todas en blanco y negro. Pero desgraciadamente, con el paso del tiempo, el jardin fue alterado de manera sustancial, por razones funcionales, eliminando alguno de los macizos y simplificando las formas diseñadas por Burle Marx, de

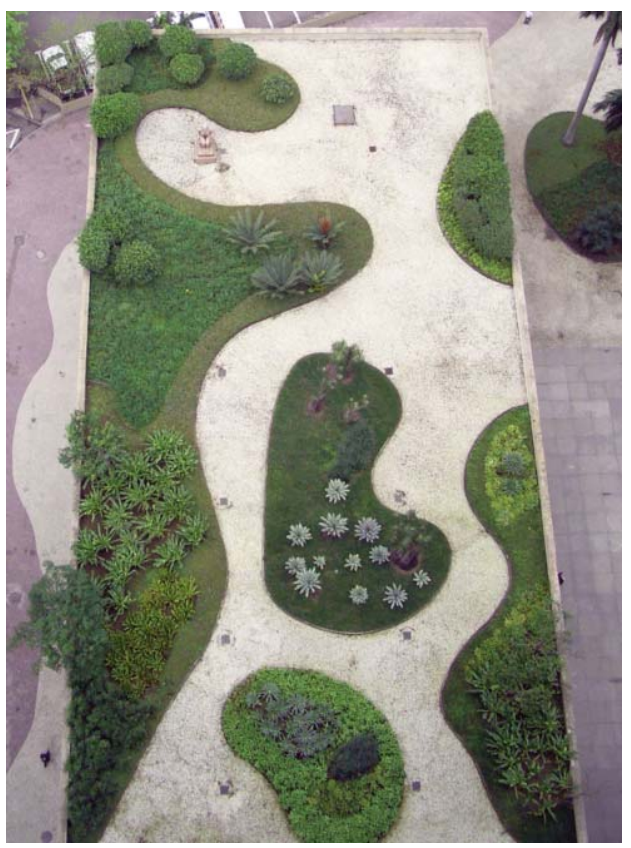

manera que el jardín actual posee muy poco del proyecto original, desaparecido casi por completo el sentido surrealista original. Solamente se mantiene un sesgo surrealista en la relación entre el jardín de la terraza y el jardín de la plaza también diseñado por Burle Marx con formas onduladas, pero sin la fuerte carga plástica de aquél. Los dos jardines fueron pensados para ser vistos desde la cubierta superior del edificio (en la cual aparecen también unas jardineras onduladas), en continuidad el uno del otro, como si estuvieran en el mismo plano, disolviendo la solidez de la arquitectura, en una especie de ejercicio de camuflaje vegetal.

El acto de "antropofagia" que Burle Marx realizó en el jardín del Ministerio no es único en su personal obra, lo podemos detectar, de una u otra manera, en otros paisajes inmediatamente posteriores, especialmente en el jardín de la cubierta del Instituto de Seguros de Brasil (Río de Janeiro, 1938), desgraciadamente desaparecido, una brillante continuación de la experimentación formal iniciada en aquel, realizado en colaboración con los arquitectos Marcelo y Milton Roberto. A pesar de las similitudes, el jardin del Instituto presenta rasgos de mayor formalidad y un grado de abstracción ligeramente inferior que el del Ministerio. ${ }^{10}$ En este caso, la planta se organiza en torno a un estanque de bordes muy ondulados, con una fuerte componente plástica, a la manera de Arp, una forma autónoma que se adosa a uno de los bordes del jardin, y que parece metamorfosearse en el resto de las formas que lo acompañan, mediante extensiones y superposiciones formales; el proceso compositivo se realiza, de nuevo, como en un collage, mediante estratos que se van superponiendo y quedan equilibrados por la sinuosidad del camino de losas separadas, que cruza la composición y parece articular todos los elementos, bordeando el agua sin tocarla. En los dibujos que ambientan el jardin, Burle Marx introduce muy acertadamente figuras femeninas que dan sentido al paisaje abstracto y parecen querer explicarlo; las curvas sensuales de sus cuerpos y las desenvueltas ondas de sus peinados y sus vestidos parecen establecer una curiosa y armoniosa empatía con las formas del jardin. ${ }^{11}$

\section{El jardin japonés}

Si observamos detenidamente las pocas fotografias que se conservan del jardín del Instituto de Seguros de Brasil podemos descubrir en ellas un cierto aire de paisaje oriental: el estanque ondulado $\mathrm{y}$, sobre todo, el camino de piedras, también ondu- 


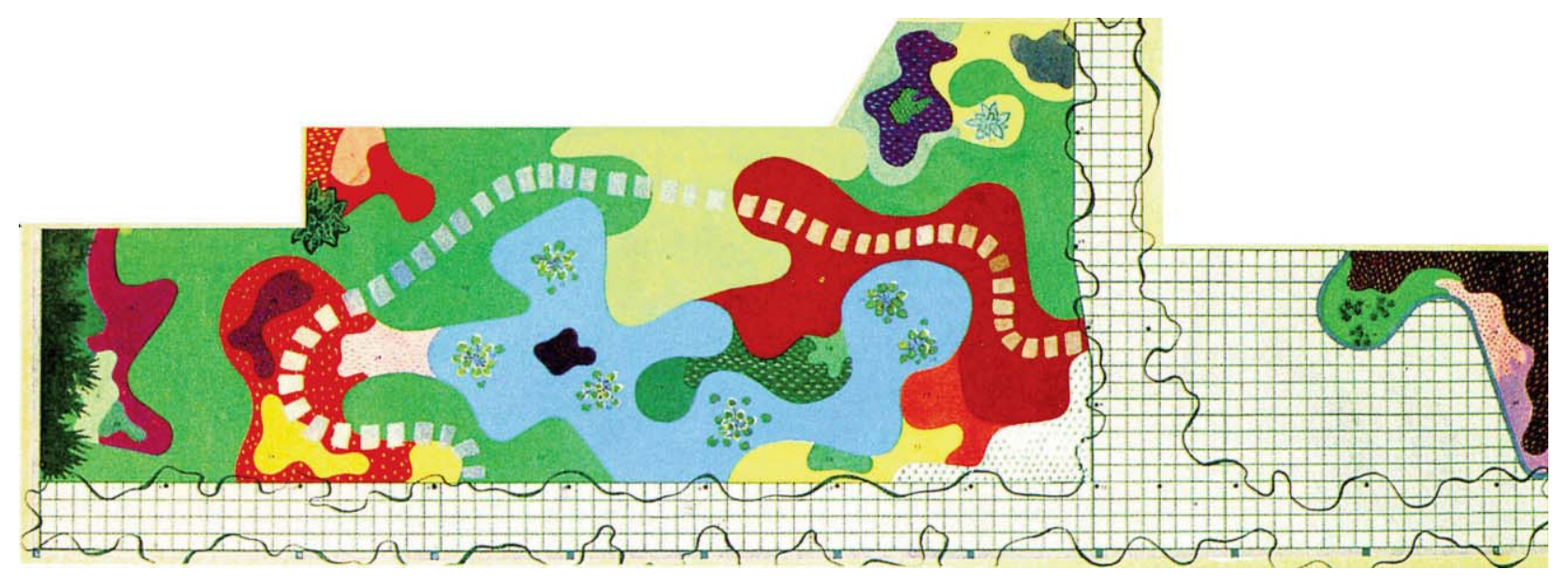

Figura 28. R. Burle Marx. Jardin en la cubierta del Instituto de Seguros de Brasil, Río de Janeiro, 1938, planta (Rizzo, 1992).

Figura 29. Jardin en la cubierta del Instituto de Seguros de Brasil, Río de Janeiro, 1938. Secuencia compositiva del jardin. Dibujo del autor.

Figura 30. Jardin en la cubierta del Instituto de Seguros de Brasil, Río de Janeiro, 1938, dibujo (Rizzo, 1992).
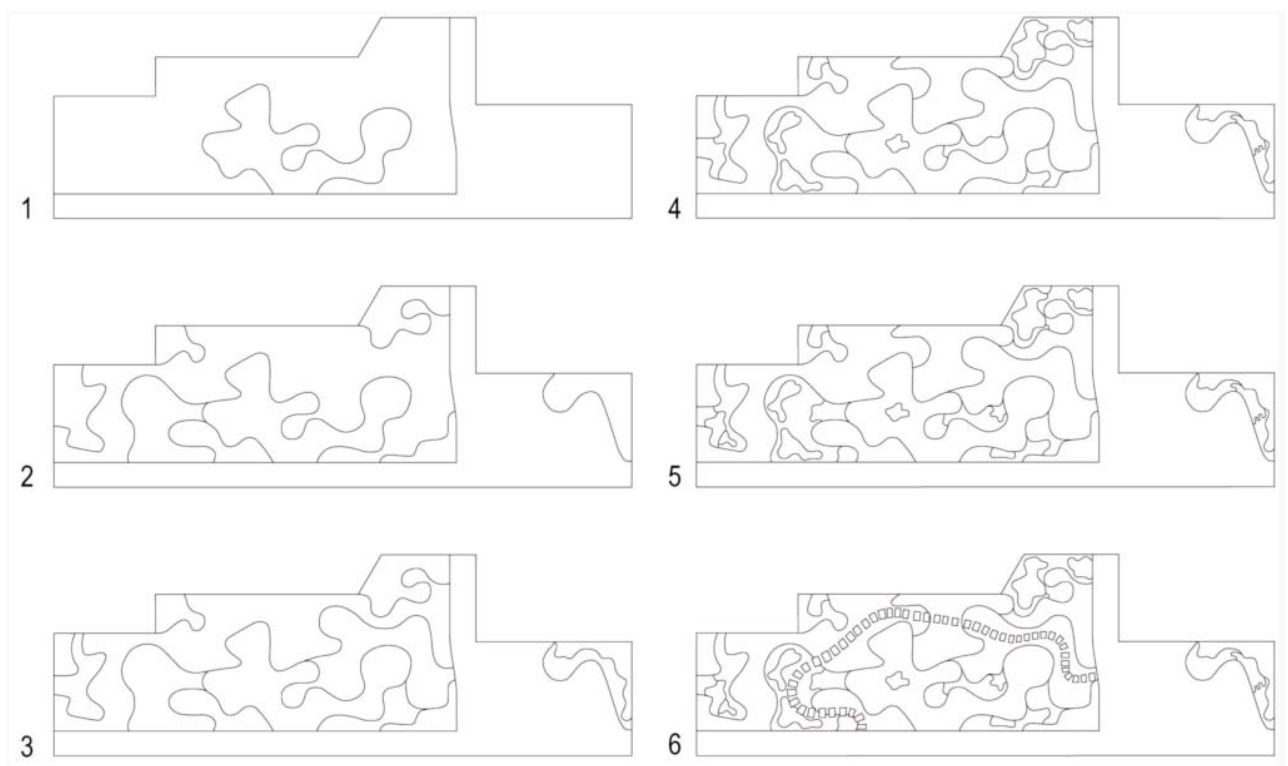

lado, que atraviesa de manera muy elegante toda la composición, parecen citas bastante evidentes a las formas del jardín japonés ${ }^{12}$, referencia que podriamos detectar también, aunque de una manera más abstracta y sutil, en el propio jardin del Ministerio. En el Instituto la cita se completa con la incorporación de la vista desde el jardín de los morros, enmarcados por ventanas apaisadas, de clara inspiración corbusieriana, un mecanismo muy similar al shakkei (tomar prestado un paisaje

exterior) utilizado habitualmente en los jardines japoneses. Esta alusión al jardin japonés permite cerrar el círculo para intentar explicar los argumentos expuestos y desarrollados por Burle Marx en sus jardines biomórficos.

El jardin japonés elabora siempre cuidadosas representaciones plásticas, y al mismo tiempo simbólicas, de paisajes naturales reales célebres, como sucede en la Villa de Katsura, realizada por el artista Kobori

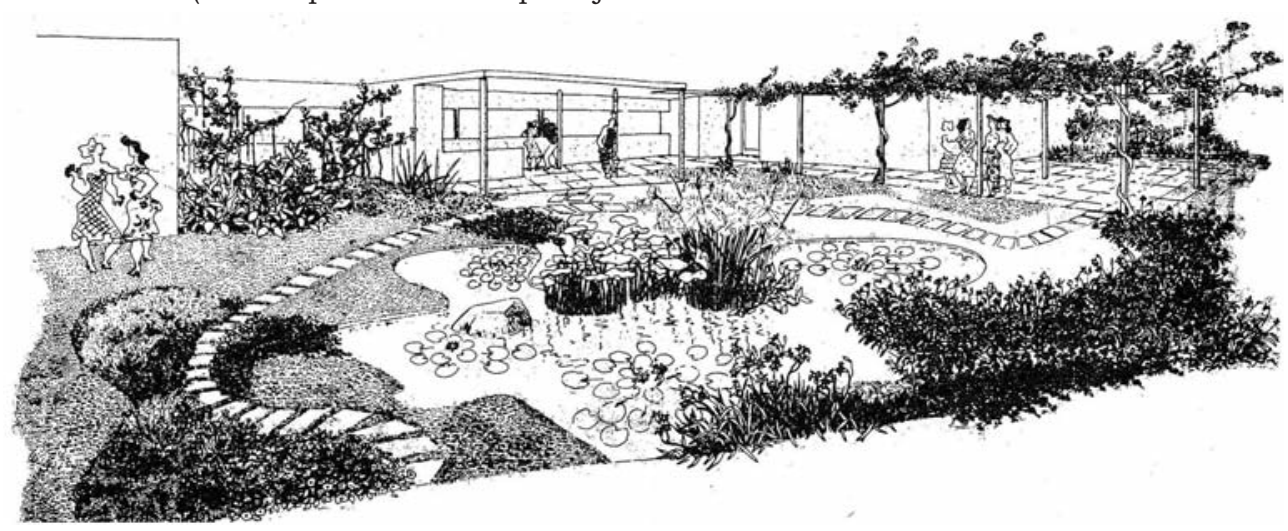


Figura 31. Jardin en la cubierta del Instituto de Seguros de Brasil, Río de Janeiro, 1938, vista (Tabacow, 2004).
Enshu en Kioto hacia 1620, una de las cumbres del diseño del jardín, con su estanque en forma de cola de grulla y sus caminos de piedras señalando el movimiento del espectador en torno al agua. Al recrear paisajes célebres a pequeña escala (en el caso de Katsura la península de Amanohashidate o "puente hacia el cielo", en la prefectura de Kioto), o evocar patrones del paisaje natural, el jardin construye una micro-geografia análoga a la natural pero especialmente recreada y mejorada para la percepción estética del observador y dotada de un claro sentido poético.

Esta alusión al jardín japonés se percibe incluso de manera más clara y evidente en otras obras posteriores de Burle Marx, especialmente en el jardín realizado para su amiga Odette Monteiro en Correias (1948). En el jardín Monteiro, la escena central se organiza en torno a un estanque

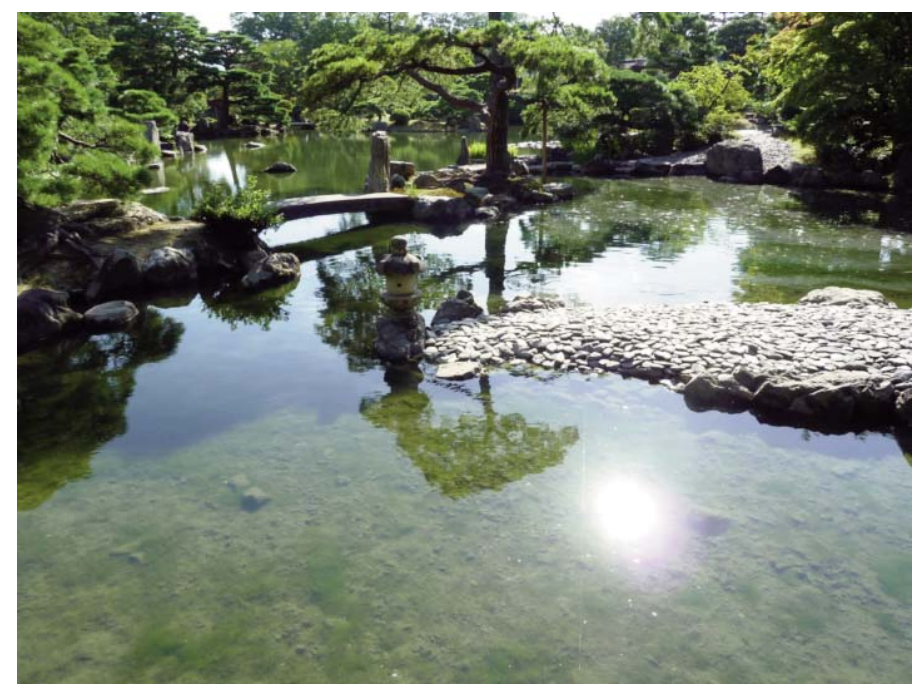

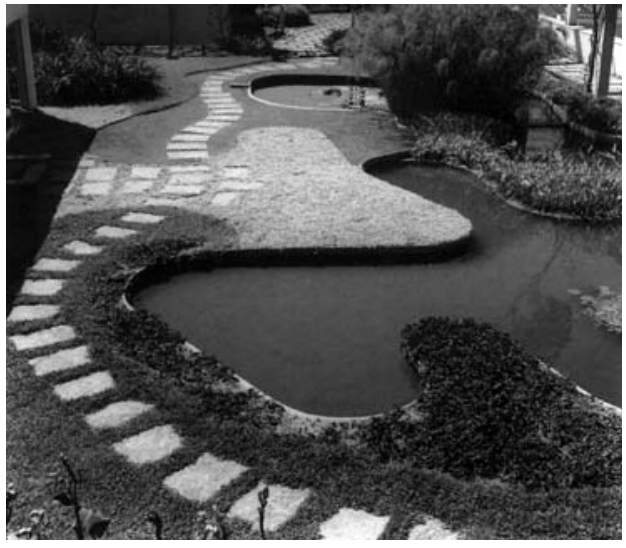

de claros tintes japoneses, cruzado por un camino de piedras separadas, como los de Katsura, acompañado de los característicos macizos ondulados de flores y arbustos, todo ello recortado sobre un paisaje fabuloso de morros que se incorporan a la escena del jardin en el mejor de los shak$k e i$. Las manchas de color de la vegetación parecen derramarse sobre la composición en un gesto puramente plástico, pictórico.

Casi al mismo tiempo que Burle Marx proyectaba el jardin del Ministerio, uno de los más conspicuos diseñadores del jardín japonés moderno, el polifacético Mirei Shigemori (arquitecto de jardines, pintor de la Escuela Nihonga, calígrafo, maestro de ikebana y de la ceremonia del té), utilizaba formas bastante similares, en un intento por establecer vínculos entre la tradición oriental y la innovación occidental. Una de las primeras obras de Shigemori, y una de las más significativas, es el "Hassô no Niwa", Jardín de las ocho fases (en alusión a los ocho niveles -el "óctuple sendero"- que debe seguir el
Figura 32. Villa Katsura, Kioto, s. XVII. Vista del estanque con la representación del paisaje célebre de

Amanohashidate (Fotografia del autor).

Figura 33. R. Burle Marx. Jardin Odette Monteiro, Correias, 1948 (Mindlin, 2000).

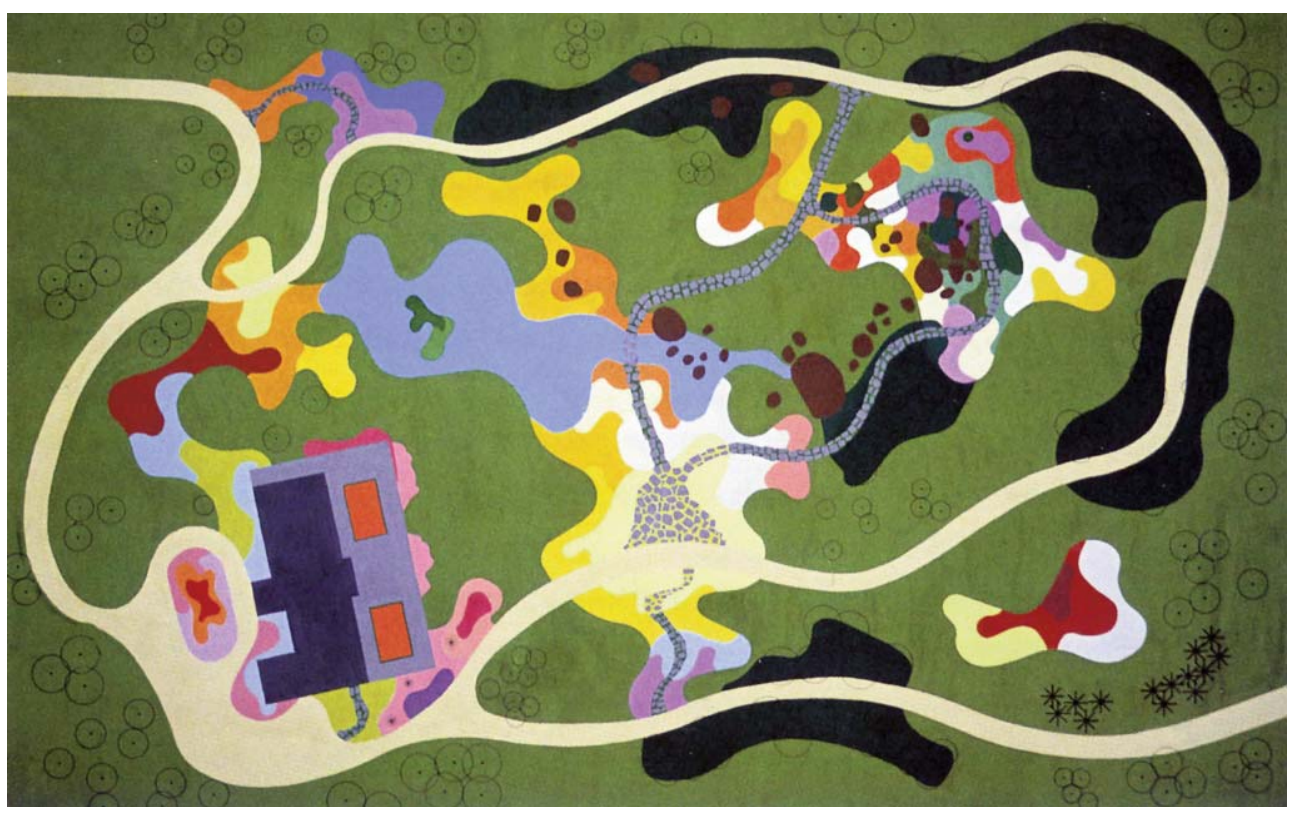




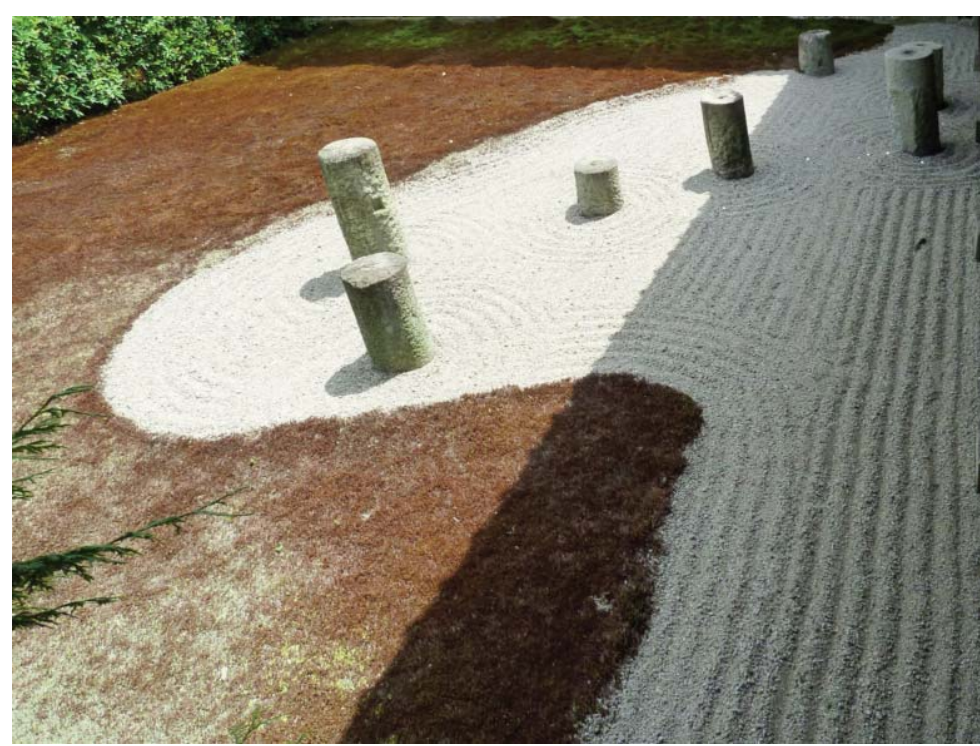

Figura 34. $M$. Shigemori. Jardin "Hokuto no niwa", Templo del Tôfuku-ji, Kioto, 1939 (Fotografia del autor)

Figura 35. $M$. Shigemori. Jardin casa Shigemori, Kioto, 1953 (Fotografia del autor).

monje zen para alcanzar el nirvana), realizado en 1939 para el templo del Tôfuku-ji (situado en los alrededores de Kioto), en torno al hôjô (pabellón principal del templo), en realidad cuatro karesansui (representando las "cuatro nobles verdades" del budismo) en la disposición tradicional, el jardín principal situado al sur y los otros tres bordeando el edificio, articulados por la tradicional plataforma o engawa que recorre todas las partes del jardín como soporte arquitectónico de la secuencia narrativa. En algunas partes de la obra, de manera especial en el jardin del Este, "Hokuto no niwa", aparecen formas onduladas que van más allá de las ondulaciones clásicas rastrilladas en las superficies de gravilla de granito, introduciendo un sentido plástico contemporáneo, cercano, como el de Burle Marx, al surrealismo pictórico.

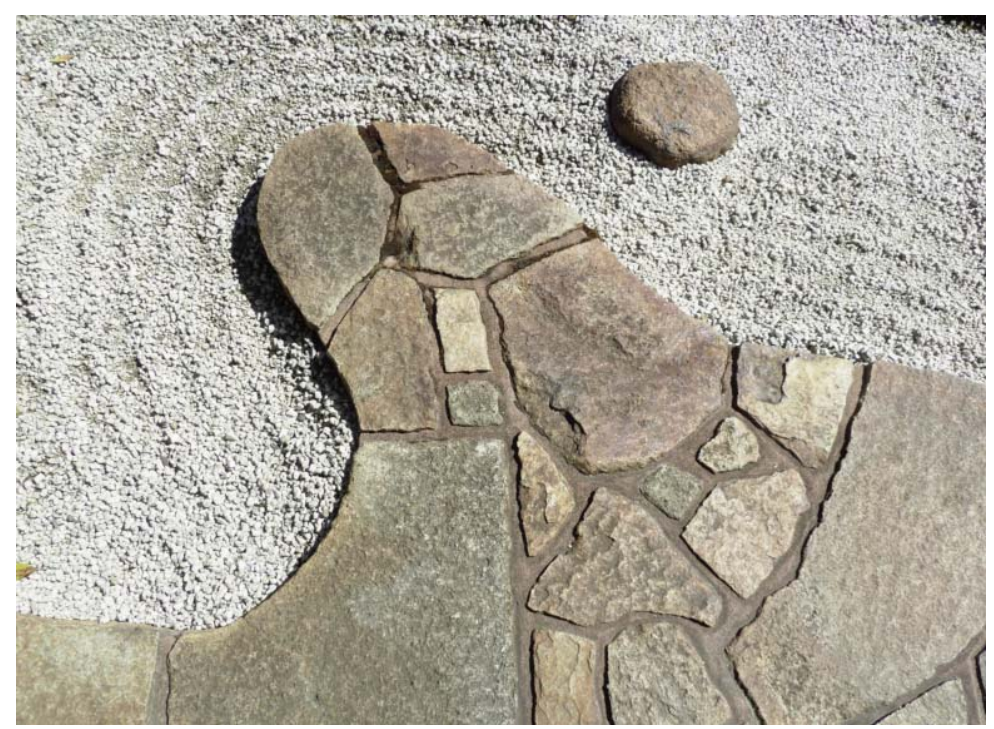

Años más tarde, en 1953, en el jardín de su casa en Kioto, Shigemori introduce una banda ondulada de pavimento muy expresiva, también de despiece irregular, que bordea la arquitectura y enmarca la composición de piedras, algo que se convertirá en una constante en sus jardines (Álvarez 2015). Las curvas del jardin recuerdan, como las de Burle Marx, a las formas de Kandinsky de Punto y linea sobre el plano, un libro bien conocido por Shigemori. Christian Tschumi (2007) sugiere una relación muy directa entre su forma de componer el jardín y la teoría de Kandinsky, de manera que los puntos serían las piedras, las líneas las ondulaciones y las superficies las materias, texturas o colores, de esta manera se establecería una linea directa entre las visiones de la vanguardia europea y la tradición japonesa a través de los jardines del diseñador.

Para cerrar el círculo, Burle Marx terminará construyemdo un auténtico manifiesto de abstracción orientalista en una de sus últimas obras, en la que recupera el pulso plenamente surrealista, el jardin en la terraza del Banco Safra en Sao Paulo (1986), una revisitación de las formas del jardín del Ministerio en clave de karesansui, un ejercicio puro de estilo, una demostración evidente de los argumentos que hemos ido desvelando sobre su obra.

\section{Conclusiones}

Los paisajes diseñados por Roberto Burle Marx, especialmente los realizados en los años 1930 y 1940, contienen una clara vocación surrealista que, con el paso del tiempo, irá ampliando su espectro a otro tipo de alusiones formales y plásticas. Estos primeros paisajes, tan intencionadamente surrealistas, surgidos de la paleta del pintor, pero construidos realmente, según la acertada reflexión de su amigo Lucio Costa ("pinta con plantas"), con materiales vegetales, tierra y agua, persiguen siempre la creación de un paraíso, figurativo unas veces y otras de corte mucho más abstracto, como sucede en el jardin del Ministerio. El surrealismo tropicalista de este jardin, paradigma de la obra del artista brasileño, parece recorrer algunos de los caminos de paisaje transitados previamente por Le Corbusier y añadir la concepción de las formas naturales de Jean Arp, consiguiendo crear un método compositivo a la manera de un collage, que se acaba alejando del automatismo onírico y se acerca a la construcción de un patrón ideal de paisaje como imagen de modernidad absoluta.

En una visión personal, y casi alucinada, de la antropofagia enunciada por Oswald 


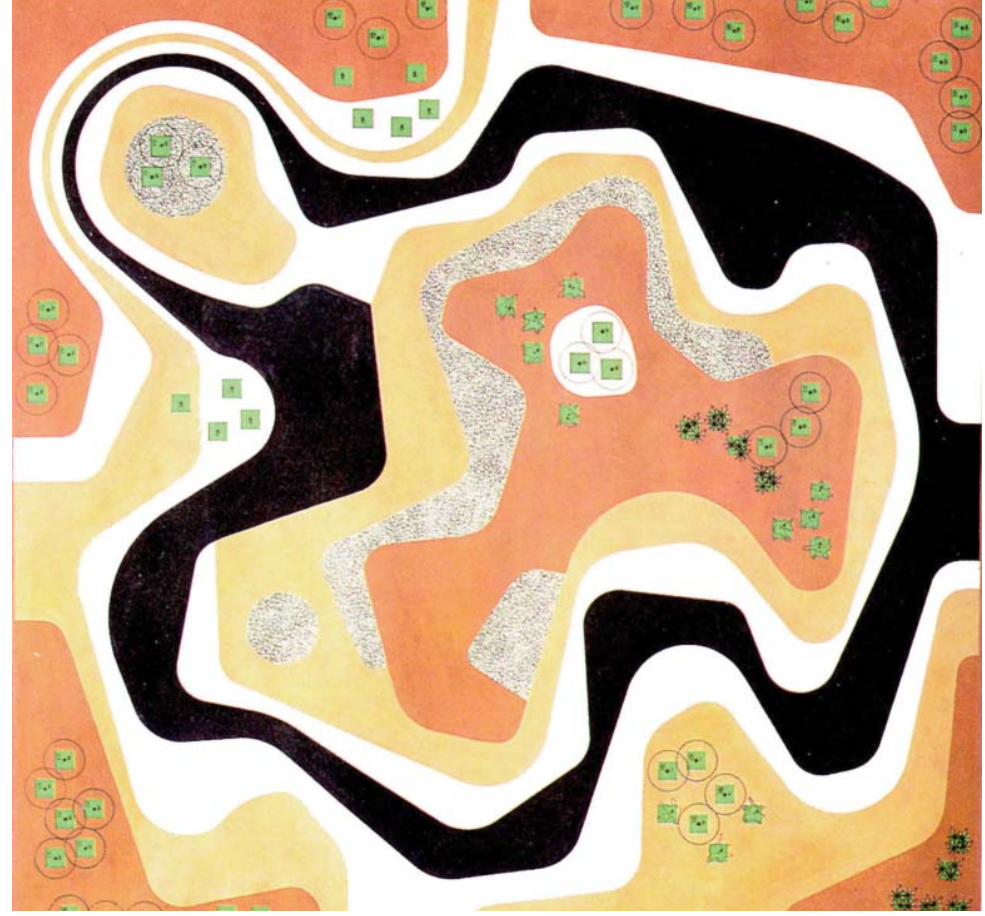

Figura 36. R. Burle Marx. Jardin en la terraza del Banco Safra, Sao Paulo, 1983-86 (Rizzo, 1992). un acto de "canibalismo conceptual"), de Andrade (lo que podríamos denominar Burle Marx fagocitó los perfiles del paisaje tropical, las formas plásticas de Jean Arp, los enunciados de Le Corbusier, las curvas tensionadas de Kandinsky, incluso las ondulaciones del jardín japonés, y lo devolvió todo, en un vómito plástico y poético sublime, convertido en formas autónomas, materializadas mediante elementos vegetales, construyendo un paisaje de estratos superpuestos, de claro matiz surrealista, identificado para siempre con la cultura moderna brasileña.

\section{Notas}

1. Leo Putz volvió a Alemania en 1933; su obra fue considerada "arte degenarado" por los nazis.

2. Desgraciadamente la casa Schwartz fue demolida y no hay mucha información sobre el jardin.

3. Auguste Perret, invitado por Capanema para dar una conferencia en 1936, habia sido consultado, antes que Le Corbusier, sobre el proyecto del Ministerio. El ministro también había invitado al arquitecto italiano Marcelo Piacentini.

4. El equipo de la Ciudad Universitaria estuvo formado por los arquitectos Lucio Costa, Affonso Eduardo Reidy, Jorge Moreira, Oscar Niemeyer, Carlos Leao, Angelo Brunhs, Firmino Saldaña, José de Sousa y Paulo Fragoso.

5. El jardin de la terraza del ministro es un verdadero experimento plástico, el de la plaza amplía de escala dicha experimentación y el de la cubierta resuelve con jardineras sinuosas un tema típicamente corbusieriano.

6. Fue el propio Le Corbusier quien convenció a los arquitectos de la utilización de un sistema tradicional en el revestimiento de un edificio funcionalista.

7. El planteamiento inicial del jardín del Ministerio sufrió ligeras variaciones de tamaño y de forma en el desarrollo del proyecto y en la construcción. El jardín construido mantuvo la esencia original, sin embargo, las restauraciones poste- riores modificaron sustancialmente la forma y eliminaron los aspectos más cromáticos de la vegetación

8. Hay que observar que la disposición de las formas principales de la composición arrancan de la relación entre el jardin y los espacios interiores, con una salida desde el despacho del ministro y otra desde la sala de despachos.

9. El jardín se complementaba con murales cerá micos realizados por Paulo Werneck.

10. De la misma manera que Oscar Niemeyer gustaba de explicar su arquitectura a partir de las curvas del cuerpo de la mujer.

11. La influencia del jardín japonés en Occidente ha sido notable en las primeras décadas del siglo XX, baste citar a F. Ll. Wright y, sobre todo, Richard Neutra.

\section{Bibliografia}

ADAms, William Howard. 1991. Roberto Burle Marx. The Unnatural Art of the Garden. Nueva York: MoMA.

ÁlVAREZ ÁlVAREZ, Dario. 2007. El jardín en la arquitectura del siglo XX. Naturaleza artificial en la cultura moderna. Barcelona: Reverté.

Álvarez Álvarez, Darío. 2015. El karesansui moderno: Mirei Shigemori e Isamu Noguchi. En Menene Gras Balaguer (ed.). El jardin japonés. Editorial Tecnos, 2015.

Amaral, Tarsila do. 2009. Tarsila do Amaral: Catálogo de la exposición. Madrid: Fundación Juan March.

ARP, Jean. 1966. Jours effeuillés. Paris: Gallimard.

ARP, Jean. 2006. Retrospectiva 1915-1966. Madrid: Circulo de Bellas Artes.

BRown, Jane. 1994. Gardens of golden afternoon. The story of a partnership: Edwin Lutyens \& Gertrude Jekyll. Londres: Penguin Books.

Dourado, Guilheme Mazza. 2009. Modernidade verde: jardins de Burle Marx. São Paulo: Senac.

Fleming, Lawrence. 1996. Roberto Burle Marx, um retrato. Río de Janeiro: Index.

Fraser, Valerie. 2000. Cannibalizing Le Corbusier. The MES gardens of Roberto Burle Marx. JSAH. Journal of the Society of Architectural Historians, 59-2: 180-193.

Jové SAndoval, José María. 2003. Alvar Aalto Proyectar con la naturaleza. Valladolid: Universidad de Valladolid.

KANDINSKY, Wassily. 1983 (1926). Punto y linea sobre el plano. Contribución al análisis de los elementos pictóricos. Barcelona: Barral.

Le Corbusier. 1999 (1930). Precisiones. Barcelona: Apóstrofe, Barcelona.

Le Corbusier et Pierre Jeanneret. 1970-75. Oeuvre complète. Zurich: Les Editions d'Architecture.

Montero, Marta Iris. 2001. Burle Marx. El paisaje lírico. Barcelona: Gustavo Gili.

Oliveira, Ana Rosa de. 2007. Tantas vezes paisagem. Rio de Janeiro: FAPERJ.

Rizzo, Giulio G. 1992. Roberto Burle Marx. Il giardino del Novecento. Florencia: Cantini.

Tabacow, José (ed.). 2004. Roberto Burle Marx. Arte \& Paisagem. Conferencias escolhidas. São Paulo: Studio Nobel.

Tschumi, Christian 2007. Mirei Shigemori-Rebel in the garden. Modern japanese landscape architecture. Basilea: Birkhäuser.

Fecha final recepción artículos: 30/04/2017

Fecha aceptación

29/06/2017

Artículo sometido a revisión por dos revisores independientes por el método doble ciego. 